NBER WORKING PAPER SERIES

\title{
PRODUCT DIFFERENTIATION, SEARCH COSTS, AND COMPETITION \\ IN THE MUTUAL FUND INDUSTRY: \\ A CASE STUDY OF S\&P 500 INDEX FUNDS
}

\author{
Ali Hortaçsu \\ Chad Syverson \\ Working Paper 9728 \\ http://www.nber.org/papers/w9728 \\ NATIONAL BUREAU OF ECONOMIC RESEARCH \\ 1050 Massachusetts Avenue \\ Cambridge, MA 02138 \\ May 2003
}

Zvi Eckstein and Alan Sorenson provided thoughtful suggestions regarding earlier drafts. We have also benefited from discussions with Judy Chevalier, Lars Hansen, Tom Hubbard, Boyan Jovanovic, Bob Lucas, Derek Neal, Ariel Pakes, Jonathan Reuter, and seminar participants at the University of Chicago, the Society for Economic Dynamics annual meeting, INSEAD, NYU, the Economic Research Center, the NBER IO meetings, Harvard/MIT, and the Chicago GSB. Arie Toporovsky, Chris Xu, and Yoo-Na Youm provided research assistance. We are grateful for the financial support of the John M. Olin Foundation. The views expressed herein are those of the authors and not necessarily those of the National Bureau of Economic Research.

(C2003 by Ali Hortaçsu and Chad Syverson. All rights reserved. Short sections of text not to exceed two paragraphs, may be quoted without explicit permission provided that full credit including (C) notice, is given to the source. 
Product Differentiation, Search Costs, and Competition in the Mutual Fun Industry:

A Case Study of S\&P 500 Index Funds

Ali Hortaçsu and Chad Syverson

NBER Working Paper No. 9728

May 2003

JEL No. L0, L1, G0, G1, G14, G20

\begin{abstract}
Two salient features of the competitive structure of the U.S. mutual fund industry are the large number of funds and the sizeable dispersion in the fees funds charge investors, even within narrow asset classes. Portfolio financial performance differences alone do not seem able to fully explain these features. We investigate whether non-portfolio fund differentiation and information/search frictions also play a role in creating these observed industry characteristics. We focus on their impact in a case study of the retail S\&P 500 index funds sector. We find that fund proliferation and price dispersion also exist in this sector, despite the funds" financial homogeneity. Furthermore, there was a marked shift in sector assets to more expensive (often newly entered) funds throughout our sample period. Our analysis indicates that these observations are consistent with the presence of both nonportfolio differentiation and information/search frictions. Structural estimation of a novel searchover-differentiated-products model reveals that reasonable magnitudes of investor search costs can explain the considerable price dispersion in the sector, and consumers seem to value funds" observable attributes - such as fund age and the number of other funds in the same fund family- in largely plausible ways. The results also suggest that the substantial increase in mutual fund market participation observed during our sample, and the corresponding purchase decisions of novice investors, drove the shift in assets toward more expensive funds. We also find evidence consistent with the presence of switching costs, as distinct from search costs. Using structural estimates of demand parameters and search costs, we investigate the possibility that there are too many sector funds from a social welfare standpoint. The results of this exercise indicate that restricting entry would yield nontrivial gains from reduced search costs and productivity gains from scale economies, but these may be counterbalanced by losses from increased market power and reduced product variety.
\end{abstract}

Ali Hortaçsu

Department of Economics

University of Chicago

1126 E. $59^{\text {th }}$ Street

Chicago, IL 60637

and NBER

hortacsu@uchicago.edu
Chad Syverson

Department of Economics

University of $\mathrm{C}$ hicago

1126 E. $59^{\text {th }}$ Street

Chicago, IL 60637

and NBER

syverson@uchicago.edu 


\section{Introduction}

An investor seeking to hold assets in a mutual fund is a consumer with many choices: in 2001, there were 8307 U.S. mutual funds in operation. If one counts different share classes for a common portfolio as separate options available to an investor, the implied total number of funds to choose from exceeds 13,000 . Note in comparison that there were a total of 7600 companies listed that year on the NYSE, AMEX, and Nasdaq combined. A mutual fund investor's choice set has also been growing robustly over time: while there were 834 mutual funds in operation in 1980 , this nearly quadrupled to 3100 by 1990 , and almost tripled again by $2001{ }^{1}$

An additional, less documented feature of the mutual fund marketplace is the enormous dispersion in the fees investors pay to hold assets in funds, a dispersion that persists despite the competition among large number of industry firms. These fee differences are not simply a result of variation across fund sectors; price dispersion within (even narrowly defined) sectors is large. Table 1 summarizes this within-sector dispersion. The table shows fund fee dispersion moments - the coefficient of variation, the interquartile price ratio, and the ratio of the $90^{\text {th }}$ to the $10^{\text {th }}$ percentile price - for each of 22 fund objective sectors in $2000 .^{2}$

As is evident in the table, the $75^{\text {th }}$-percentile-price fund in a sector-year cell typically has investor costs about twice those of the $25^{\text {th }}$ percentile fund. The $90^{\text {th }}-10^{\text {th }}$ percentile price ratios indicate between three- and seven-fold fee differences within sector-years. The extrema of the distribution (not shown) can exhibit vast dispersion; the minimum-price aggressive growth fund, for example, imposed annualized fees of only 14 basis points (i.e., $0.14 \%$ of the value of an investor's assets in the fund), whereas the highest-price fund charged a whopping 1670 basis points. While some of these sectors are fairly broad and may include funds with very different portfolios, dispersion remains even within what are plausibly quite specialized sectors. The table's second panel shows the same dispersion measures for four randomly selected specialized

\footnotetext{
${ }^{1}$ The expansion of the choice set has accompanied a steady increase in the fraction of the population taking advantage of the mutual fund option. Only $6 \%$ of households held mutual funds in 1980 . By 2001 , fully $52 \%$ of U.S. households held assets in mutual funds.

${ }^{2}$ Throughout the paper, we refer to funds' annualized fees as "prices" to reflect the fact that from the investor's perspective, these fees are the cost of buying the right to hold assets in a fund. The fund data used to calculate these figures is from the Center for Research in Security Prices (CRSP). Roughly 95 percent of the funds in the CRSP database are matched to one of these sectors, which are categorized according to the Investment Company Data, Inc. (now Standard and Poor's Micropal) system. Fund prices are annualized investor costs, calculated according to the literature standard of annual fees (both management fees and 12b-1 fees if applicable) plus one-seventh of any loads. While this is a simplification of what are in some cases rather complicated nonlinear pricing schedules, we feel it is a reasonable approximation. We have checked the robustness of our primary empirical results to other price definitions. The paper's data appendix discusses the data in greater detail.
} 
sectors (these are based on Strategic Insight's classification system, which is considerably finer than the above taxonomy). There is a modest drop in price dispersion compared to the broader sectors, but considerable differences still remain. ${ }^{3}$

Of course, fund portfolios can vary considerably even within narrow asset classes. Fund price dispersion might then reflect within-sector differences in demand or cost structures across portfolios. On the demand side, certain portfolios will outperform their sector cohorts; higher prices may just reflect investors' willingness to pay for better performance. As for costs, fund managers choose different securities with which to comprise their portfolio, and some of these securities may be more expensive to analyze or trade than others. Fund prices may reflect this fact. ${ }^{4}$ Portfolio differentiation, too, may explain in part the other salient fact discussed above: the large number of industry funds. Investors may differ in their ideal portfolios and their current asset compositions. Perhaps thousands of funds (and the several hundred new funds each year) are necessary to meet the demand for the many risk-return profiles sought by investors. ${ }^{5}$

However, a look at the retail (i.e., non-institutional) S\&P 500 index fund sector strongly suggests that the composition and financial performance of funds' portfolios are not the only factors explaining fund proliferation and fee dispersion. All funds in this \$164 billion (in 2000)

\footnotetext{
${ }^{3}$ The competitive effect of entry appears to be weak throughout the industry. Entry coincides with increases in both average fees and fee dispersion. We regress sectoral price (fee) dispersion moments for 1993-2001 on the logged number of sector funds, allowing for sector-specific intercepts and trends. The results, available from the authors, show that average fees in the sector actually increase significantly as the number of sector funds rises. The assetweighted mean also increases (albeit insignificantly). Several fee dispersion moments (standard deviation, coefficient of variation, interquartile range, and the $90^{\text {th }}-10^{\text {th }}$ and $95^{\text {th }}-5^{\text {th }}$ percentile fee ranges) are positively correlated with increases in the number of sector funds as well.

${ }^{4}$ To check whether price dispersion plausibly reflects performance differences across funds, we regress gross annual returns, the within-year average gross monthly return, and the within-year standard deviation of monthly returns on fund prices. The sample consists of all mutual funds in the CRSP database between 1993 and 2001 with return data available - roughly 83,300 fund-year observations. The specifications include interacted Strategic Insight objective category (of which there are 193) and year effects, so estimated coefficients reflect the correlation between returns and prices within sector-year cells. The price coefficients in both gross return regressions are actually negative (though statistically insignificant); more expensive funds have lower-than-average returns. (A regression of net annual returns on price yields a significantly negative coefficient; one would expect zero in a perfectly competitive market where price differences are exactly compensated by gross returns.) Furthermore, the correlation between fund prices and return variance is positive and significant - also the opposite sign one would expect if performance and price were closely linked. A more careful investigation would obtain measures of expected returns and use longer performance histories to measure within-fund return variation; however, given the magnitude of the observed price dispersion, these results suggest that the price-performance link is not an overwhelming determinant of the patterns observed in the data. The findings are also in line with Carhart (1997), where the impact of expenses on performance was negative and at least one-for-one. Detailed results are available from the authors upon request.

${ }^{5}$ See Mamaysky and Spiegel (2001) for an argument along these lines.
} 
sector explicitly seek to mimic the same performance profile, that of the S\&P 500 index. Thus any discrepancies among these funds' financial characteristics should be minimal, and the observed competitive structures of the sector (including the important fund proliferation and price dispersion issues discussed above) are likely to be driven by non-portfolio effects.

It is readily apparent that, despite the sector's financial homogeneity, the features of the broader mutual fund industry are equally prominent. There were 85 retail S\&P 500 index funds operating in 2000, even though each one offered plausibly equivalent expected risk-return profiles, a number that seems well beyond the saturation point arising from simple portfolio choice motives. Entry has been brisk too: the number of funds in the sector has more than quintupled since 1992. ${ }^{6}$ As for price dispersion, the highest-price S\&P 500 index fund in 2000 imposed annualized investor fees nearly 30 times as great as those of the lowest-cost fund: 268 vs. 9.5 basis points. This striking divergence is not restricted to the far ends of the distribution; the $25^{\text {th }}$ and $75^{\text {th }}$ percentile prices are 47 and 144.8 basis points, respectively - an over three-fold difference, and higher than any of the broader sectors outlined in Table 1 . The $90^{\text {th }}-10^{\text {th }}$ percentile ratio is also a comparatively high 8.2. Even more interestingly, high-price funds are not all trivially small. The highest-fee fund held 1.1 percent of sector assets - enough to make it the tenth-largest fund in the sector and not much smaller than the 1.4-percent share of the lowestprice fund. ${ }^{7}$

That so many funds, with such diffuse prices, operate even in a sector of plausibly financially homogeneous funds is a puzzle we seek to address. We investigate whether two sources of price dispersion are at work in the retail S\&P 500 index fund sector: consumers' tastes for product attributes other than portfolio composition, and/or informational (or search) frictions that deter investors from finding the fund charging the lowest management fee. Below, we model a competitive equilibrium that simultaneously incorporates these two elements. We

\footnotetext{
${ }^{6}$ Throughout this paper, we follow the CRSP convention (also common in the literature) of treating each fund share class in multi-class funds as a separate fund. Multi-class funds are those which have a common manager and portfolio, but have different pricing schemes and asset purchase and redemption rules. To give an idea of the relative prevalence of multiple-share-class portfolios in the sector, if we were to count multiple-class funds as single funds, there would be about 50 funds in 2000. We also include exchange-traded funds (ETFs) based on the S\&P 500 index. ETFs are essentially mutual funds that can be traded in a stock market. There is only one ETF for most of our sample, Standard \& Poor's Depositary Receipts (SPDRs). In 2000, a second ETF started trading, Barclay's iShares S\&P 500 Index Fund.

${ }^{7}$ The sizeable price dispersion is not driven simply by loads; considerable spreads are observed among annual fees (the sum of management and 12b-1 fees) alone. The comparable dispersion measures for these fees are as follows: $75^{\text {th }}-25^{\text {th }}$ percentile price ratio $=2.1 ; 90^{\text {th }}-10^{\text {th }}$ percentile ratio $=6.0$; and max-min ratio $=20.8$.
} 
derive equilibrium conditions and evaluate the ability of search and non-portfolio differentiation to qualitatively and quantitatively explain patterns in the data. We then apply the model's estimates to measure the social welfare implications of having so many funds delivering what are arguably ex-ante identical returns.

We find that fairly small search costs can explain the considerable price dispersion in the sector. Furthermore, the distribution of search costs across investors has been shifting over time. While search costs were falling in the lower three quartiles of the distribution through the late $1990 \mathrm{~s}$, costs at the high end of the distribution rose. We speculate that this is a result of a composition shift: the documented influx of novice (and high-information-cost) mutual fund investors during the period. The purchases of these novice investors may also be responsible for the observed shift in sector assets to more expensive (and often newly entered) funds. We find that consumers appear to value funds' observable non-portfolio attributes, such as fund age, the total number of funds in the same fund family, and tax exposure, in largely expected ways. We also find that pricing practices that increase switching costs of investors tend to increase fund market share. Our welfare calculations indicate that restricting sector entry to a single fund would yield nontrivial gains from reduced search costs and productivity gains from returns to scale. However, these gains may well be counterbalanced by losses from monopoly market power and reduced product variety. We believe that our results are consistent with search and non-portfolio differentiation playing an important role in the retail S\&P 500 index fund sector. They also suggest that these two features may help explain observations about the industry as a whole.

We see the broader contribution of this paper as twofold. The broad mutual fund literature typically focuses on fund company operation in isolation from other market firms; it is not directly concerned with strategic interaction among industry firms. ${ }^{8}$ This paper seeks to partially fill this gap by closely exploring the nature of the industry's competitive structure. We believe that this is a potentially very fruitful area of research; competitive forces directly affect the fortunes of individual funds and fund families as well as consumer welfare. ${ }^{9}$

\footnotetext{
${ }^{8}$ This literature, too vast to cite comprehensively, follows from the classic contributions on portfolio theory and empirical testing as well as the principal-agent framework. See, for example, Jensen (1968), Malkiel (1995), Falkenstein (1996), Gruber (1996), and Chevalier and Ellison (1997, 1999).

${ }^{9}$ We should note that there has been a recent increase of interest among financial economists in the competitive structure of the mutual fund industry. For example, Sirri and Tufano (1998) note that mutual fund flows are relatively insensitive to management fees and excessively sensitive to past performance (as opposed to expected
} 
An additional contribution of the paper is methodological: the empirical modeling and estimation framework developed here can be applied to other industries where search frictions co-exist with product differentiation. Unlike previous empirical applications of models of search equilibrium (mostly in labor economics), we do not have data on individual consumers' (workers in the labor context) decisions, and must draw inferences regarding search behavior from aggregate price and quantity data. ${ }^{10}$ Our methodology is closest in this respect to the work of Hong and Shum (2001), who discuss identification and estimation of equilibrium search models using only market-level price data. Our model extends their results considerably by showing how aggregate quantity data, when combined with price data, allows one to estimate much richer models in which products are vertically differentiated. As noted below, there are also close ties between our search framework and discrete-choice demand models of McFadden (1974) and Berry, Levinsohn, Pakes (1995).

We proceed as follows. The following section provides more detail regarding the competitive patterns in the retail S\&P 500 index fund sector. In Section III, we discuss suggestive evidence regarding the importance of product differentiation and search in the sector. Section IV constructs a model of consumer search over differentiated funds and the optimal pricing responses of mutual fund companies. In section $\mathrm{V}$ we estimate the obtained equilibrium equations under several sets of assumptions about the relative importance of search and product differentiation. These results are compared and tested for robustness. We estimate in Section VI the welfare implications of limiting entry into the sector. Section VII concludes.

\section{An Overview of the Retail S\&P 500 Index Funds Sector}

Index mutual funds hold portfolios tied to a particular market index; S\&P 500 index funds are the most popular type of these funds. Index funds are passively managed; fund managers do not actively choose the stocks that compose the fund's portfolio. Instead, managers attempt to mimic the return patterns of an index, the S\&P 500 in this case. One way to

performance). Khorana and Servaes $(1999,2001)$ empirically explore what market characteristics are correlated with fund entry and the market share of fund families. Barber, Odean, and Zheng (2001) find that fund inflows seem to be more responsive to some price instruments than others, and that advertising appears to be an effective tool for increasing fund assets. On the theoretical side, Massa (2000) and Mamaysky and Spiegel (2001) explore the driving forces of fund creation.

${ }^{10}$ Sorensen (2000) is a recent attempt in the industrial organization literature to estimate search costs using consumer-level product choice data. Examples of structural estimation of search models in labor markets include Flinn and Heckman (1982), Eckstein and Wolpin (1990), and van den Berg and Ridder (1998). 
accomplish this is to hold index equities in the same proportions as their index weights. Other index-matching methods can also be used, including statistical sampling and the use of index derivatives, especially for those funds that track very broad indices with a large number of component stocks.

The fact that all funds in the S\&P 500 index sector mimic a common return pattern is useful. Restricting our attention to funds which are plausibly (ex-ante, at least) financially homogeneous allows us to isolate the roles of search and non-portfolio fund differentiation. ${ }^{11}$ The evidence does suggest considerable financial performance homogeneity in our sample. Table 2 contains summary statistics of our sample funds' gross annual returns as well as the yearly average and standard deviations of their monthly gross returns. ${ }^{12}$ As can be seen, the relative dispersion in return patterns is quite small. The interquartile range of gross annual returns is no greater than 0.32 percentage points, and is typically about $1 \%$ of the median value. ${ }^{13}$ The dispersion of average monthly returns across funds is similarly slight: the largest interquartile range is less than 0.03 percentage points and the average interquartile range-median ratio is 0.014 . This ratio for the standard deviation of monthly returns is typically less than 0.01 , and the coefficient of variation is under $5 \%$ in every year. These small variations suggest investors would be justified in presuming common ex-ante returns among our funds. ${ }^{14}$

As we document above, despite this homogeneity in financial performance, the sector shares the fund proliferation and price dispersion traits seen in the broader mutual fund industry. The sector has also seen robust entry, and both average prices and price dispersion have increased despite the large number of new sector funds. This is particularly puzzling given what

\footnotetext{
${ }^{11}$ We exclude institutional S\&P 500 funds from our sample, despite the fact that they also mimic the same performance profile, because we believe they operate in a fundamentally different product market than noninstitutional funds (more on this below). By doing so, we hope to further control for unobservable differences across funds that might confound our analysis.

${ }^{12}$ Statistics in the table correspond only to funds operating every month in observed year, in order to eliminate any composition bias from funds with return data spanning only a possibly non-representative portion of the year.

${ }^{13}$ While these patterns are largely mirrored in the standard deviations of the return moments, outliers do enlarge the standard deviation of annual returns in some years, to as much as $14 \%$ of the mean in 2000 . An index fund's performance can deviate from the index which it is tracking (and from other funds tracking the same index) because of several factors. These include idiosyncratic portfolio sales required to meet the particular daily activity needs of a fund, how much of the fund's assets are held in cash, and the timing of trades.

${ }^{14}$ As with the broader sample discussed above, a regression using our S\&P 500 funds indicates a significantly negative correlation between net annual returns and price, suggesting higher prices are not being compensated by higher gross returns of equal size. Also as with the broader sample, a regression of the standard deviation of funds' monthly returns on price indicates a positive and significant correlation. This is of course the opposite sign predicted by a close price-performance link. (Year fixed effects are included in both regressions.)
} 
the seemingly high substitutability of the funds' portfolios. We model below a competitive equilibrium that implies facts observed in the data while still allowing sector funds to be financially homogeneous.

Figure 1 plots the vigorous growth in both the number of retail S\&P 500 index funds and their total net assets under management from 1995 to 2000 . This growth was coincident with the overall growth in the mutual fund industry documented above, but was even stronger. The number of sector funds more than tripled from 1995 to 2000 (from 24 to 85), and sector assets grew over the period at twice the rate as did total equity fund assets. ${ }^{15}$

Figure 2 and Table 3 show the evolution of the sector's price distribution over our sample period. A striking feature of Figure 2, which plots the cumulative price distribution functions of sector funds, is the steady rightward shift in the price distribution from 1996 to 1999. (This trend interestingly reversed in 2000.) The movement was steady and broad; the 1997 and 1998 distributions mark continuities in the evolution, and the shift occurred throughout the distribution (but particularly at the high end). This shift occurred despite the entry of nearly a dozen funds a year during the period. Along with the increase in average price evident in the figure, Table 3 documents a corresponding increase in price dispersion: both the interquartile and the $90^{\text {th }}-10^{\text {th }}$ percentile ranges increase (though not monotonically) over the observation period. Moreover, these greater price spreads result, even though the lower quantiles increase because of larger increases at the higher end of the distribution.

An interesting related observation is the change in the relative market shares of the highand low-price segments. It is evident in Figure 3 that while low price funds capture a dominant market share, the asset share of funds in the lowest price decile has fallen consistently since 1995. In contrast, the market shares of the upper quartile and decile rose during the same period. The proportional rise in the amount of sector assets held in top price decile funds has been especially stark, rising from virtually zero to nearly $2.5 \%$. The reallocation of market share to higher-priced funds resulted in a 20\% rise in the sector's asset-weighted average price from 1995 to 2000 , from 26.8 to 32.2 basis points.

These facts document that the proliferation of sector funds has been accompanied by

\footnotetext{
${ }^{15}$ The growth was driven in part by the growing popularity of passive management strategies among investors. The S\&P 500 index fund sector was particularly able to capitalize on this preference shift partly because the original index fund, the First Index Investment Trust, is today the Vanguard 500 Index Fund. Its early entry into a growing sector has been seemingly very important: the Vanguard 500 Index Fund still is a dominant player in the sector.
} 
upward trends in both the dispersion, as in the general industry, and central tendency of their price distribution. Average investor costs have continued to rise despite the significant amount of entry into the index fund marketplace. Indeed, if the asset-weighted mean price had held constant at 1995 levels, total annualized fees would have been $\$ 88.5$ million lower in 2000 .

Figure 4 sheds additional light on this issue, plotting numbers of entrants in low- and high-price groups. From 1995 through 1999, 25 funds entered the market with prices above 100 basis points. In contrast, only seven funds charging less than 40 basis points entered. A breakdown of the asset-weighted average sector price growth, shown in Table 4, quantifies this more specifically by accounting for fund market shares. The decomposition-used in another context by Foster, Haltiwanger, and Krizan (2002) — breaks annual changes in the (asset-based) market-share-weighted average price (i.e., $\left.\bar{P}_{t}=\sum s_{i, t} p_{i, t}\right)$ into five components: within, between with fixed prices, between covariance, entry, and exit. ${ }^{16}$ As Table 4 indicates, entry's net price effect is positive for all years except 2000 (note, however, that the share-weighted average price still increased from 1999 to 2000 despite the shift in the unweighted price distribution). Moreover, for the two years with the largest average share-weighted price increases (1998 and 1999), entry was the predominant factor. The within component is interestingly negative from 1996-1999, indicating average incumbent fund prices were decreasing.

The model of sector equilibrium that we construct below can shed light on many of these facts. First and foremost, it shows how a large number of funds with dispersed prices can be sustained in equilibrium despite financial homogeneity. It furthermore reflects a possible explanation for the shift to more expensive funds during the great asset run-up of 1998-99. It allows us to estimate the shape of the investor search cost distribution at given points in time and track the distribution's evolution throughout the sample. The model also allows us to estimate

${ }^{16}$ This decomposition is defined as follows:

$$
\Delta \bar{P}_{t}=\sum_{i \in C} s_{i, t-1} \Delta p_{i, t}+\sum_{i \in C} \Delta s_{i t}\left(p_{i, t-1}-\bar{P}_{t-1}\right)+\sum_{i \in C} \Delta s_{i t} \Delta p_{i, t}+\sum_{i \in N} s_{i, t}\left(p_{i, t}-\bar{P}_{t-1}\right)-\sum_{i \in X} s_{i, t-1}\left(p_{i, t-1}-\bar{P}_{t-1}\right)
$$

where $i$ denotes a particular fund, $s_{i, t}$ and $p_{i, t}$ are the asset share and price of fund $i$ in year $t$, respectively, $C$ is the set of incumbent funds in $t$ continuing operations from $t-1, N$ is the set of funds that enter in $t$, and $X$ is the set of funds that exit in $t-1$. The first term - the "within" component-measures that portion of the price change accounted for by the price changes of continuing funds, holding asset shares constant. When a continuing fund lowers its fees from one year to the next, this term becomes more negative. The second term captures market share reallocation between funds that are priced above or below the previous period's average prices; it is negative when relatively low (high) price funds gain (lose) market shares. The third is another between-component that captures the covariance between price and market share changes among continuing funds. The fourth and fifth terms capture the effect of entrants and exits, respectively; they are positive when entrants (exits) have higher prices than the sector average. 
how investors value fund attributes.

\section{Sources of Price Dispersion}

We have documented above that portfolio differentiation is an unlikely source of the observed price dispersion. How can an equilibrium characterized by a large number of homogeneous risk-return profile funds with disparate prices and entry predominantly in the highprice segment be sustained? In this section, we briefly discuss some empirical evidence shedding light on this question to motivate our model of industry equilibrium.

Fund attributes other than portfolio composition are one possible reason investors would value certain funds differently. If portfolio returns come bundled with a set of services, and these services differ across funds, it is quite likely that price dispersion would be observed in equilibrium. Capon, Fitzsimmons and Prince (1996) report from a survey administered to roughly 3400 mutual fund holders that investors consider the number of other funds in the fund's family and the fund company's responsiveness to enquiries as the third- and fourth-most important criteria (respectively, after performance and manager reputation) in their mutual fund purchase decision. These fund attributes are not directly related to the particular financial characteristics of a fund's portfolio, and could well account for price differences across funds with equivalent return profiles.

There are other such attributes that one might expect to play a similar role. For example, the provision of financial advice, which is usually bundled with purchase for load funds, seems to play an important role in mutual fund investment decision: $60 \%$ of investors reported consulting a financial adviser before purchase (Investment Company Institute 1997). We explore this influence in detail below. Another important product attribute is a fund's status as an exchange-traded fund (ETF). ETFs have special features investors may value such as enhanced liquidity and intra-day share valuation. Funds differ in age; for various reasons, investors might prefer an older, established fund that they are more familiar with. Investors may also favor fund managers with longer tenures, perhaps as a signal of skill or experience (recall that there is some variation in return patterns that might be affected by trading or cash/equities asset allocation abilities). Funds can have divergent taxable distribution rates for a given return pattern; clearly, investors prefer less tax exposure, all else being equal. Account service quality differences, such as the frequency and quality of account statements and publications, the hours 
phone access to accounts and/or financial advisers is available, check-writing privileges, etc., may also be important sources of non-portfolio differentiation.

An additional (but not mutually exclusive) possibility beyond product differentiation is that informational frictions sustain the observed price dispersion. There is a large theoretical literature that constructs price dispersion in homogenous product markets using costly search models (e.g., Burdett and Judd 1983, Carlson and McAfee 1983, Stahl 1989). Given the large number of mutual funds offered, it seems reasonable to assume that information-gathering investments are necessary before investors decide between fund alternatives. The presence of a sizeable market to help reduce the search costs of investors supports this notion. Several commercial mutual fund ranking services exist (Morningstar, Lipper, Valueline, etc.), and many internet portals like Yahoo! offer extensive mutual fund information. There is now even a specialized index funds site, IndexFunds.com. Many fund companies spend considerable sums on marketing and distribution, also consistent with (although neither necessary nor sufficient for) the presence of investor search. Survey evidence also suggests considerable informationgathering. The Investment Company Institute (1997) reports that surveyed investors consulted a median of two source types (four for those who had consulted a fund-ranking service) reviewing a median of 14 different information items (gross returns, relative performance, etc.) - before their most recent purchase. ${ }^{17}$ To the extent that consulting and analyzing such information consumes investor time and money, these activities constitute costly search.

Aside from this anecdotal evidence, there is somewhat more direct evidence about the importance of search frictions in the S\&P 500 index fund sector. As we mentioned before, we do not include institutional-class S\&P 500 index funds in the analysis because of our belief that they operate in a fundamentally different product market. The very high initial minimum investment levels (typically at least $\$ 1$ million) restrict demand to a fairly narrow class of investors. It also implies that if there is investor search, there is a larger gain (in absolute levels) to finding a lower-price and/or higher-quality fund for a typical institutional buyer than for a retail investor. It might then be reasonable to assume there are higher search intensities among institutional funds, implying less price dispersion and lower average prices. The data are consistent with this.

\footnotetext{
${ }^{17}$ Professional financial advisers, articles in the financial press, fund prospectuses, and fund annual reports were cited as the most common source types. The survey was administered at the very beginning of internet access diffusion among the general public, so online sources were cited as sources of pre-purchase information by only $6 \%$ of investors. This number has almost surely risen, raising the possibility that per-fund search costs have declined since the beginning of our sample period. We address issue this in depth below.
} 
Figure 5 compares histograms of institutional and retail fund prices in 2000. It is readily apparent that the former distribution is considerably tighter and has a smaller mean. While administrative cost advantages may be in part responsible for the lower average price of institutional funds, they are unlikely to affect price dispersion. While we cannot rule out all other explanations for these differences, this prima facie evidence for search is suggestive.

Entry patterns in the data also shed light on the likely sources of price dispersion. There is an element of "me-too" entry in the sector-fund families specializing mostly in actively managed funds decide to setup an S\&P 500 index fund. One might conjecture that most demand for these entering S\&P 500 funds (which are typically high-priced, as we have shown) comes from investors already holding assets in the fund family. We cannot check this directly, since we do not observe inter-fund asset flows, but it strikes us as a reasonable explanation for some of the empirical observations detailed above. One explanation for why these investors do not move their money to a lower priced fund managed by another company is somewhat distinct from product differentiation and search: switching costs. With such costs, the investor is perfectly informed about the utility benefit of moving her money to another fund, but has to incur a switching cost to remove assets from the fund company. This cost could either be "formal" (a deferred or rear load) or "informal" (the hassle associated with calling the fund company, or at worst, writing a letter to approve withdrawals).

However, the presence of search costs is also consistent with the observed entry pattern: the investor knows the utility benefit from staying but has to incur a cost to learn the utility benefit from putting her money in another fund; thus search frictions create the demand inelasticity sustaining entry. Observe that the main difference between the search vs. switching costs frameworks is the information available to the investor - hence separately identifying these two factors requires us to exploit variation in investors' information sets. Unfortunately, it is very difficult to perform this decomposition without detailed investor-level data. Given the conceptual similarity between the two costs, however, we expect comparable empirical effects and recognize that some switching-cost effects are likely to be reflected a modeling framework that focuses on search costs. A broader interpretation of our results is then appropriate.

We can, though, point to some evidence suggesting that informational search costs are a more comprehensive burden on sector investors than switching costs. For instance, formal switching costs are not pervasive in the retail S\&P 500 index fund sector. The great majority of 
sector assets - over $86 \%$ - are not subject deferred or rear loads. While some informal switching costs almost surely exist, we believe that these costs are likely smaller than those incurred in the investment decision process. Furthermore, models of competition in markets where switching costs are important (e.g., Klemperer 1989) imply that entrants should raise prices after entry and that arrival of new consumers spurs a price war. We do not observe either case in the sector. Of the 49 funds entering between 1995 and 1999, only 15 raised prices the year after entry, and only five by more than ten percent. And despite the large increase in mutual fund holding across households over the sample, there was no price war in the sector; indeed, we have documented that average prices increased. ${ }^{18}$ Also, the concept of a typical investor locked into holding assets in a single fund family due to switching costs is inaccurate: the Investment Company Institute (2000) reports the median number of mutual fund companies with which investors hold assets is two. Finally, we account in our model for the possibility that investors purchase decisions depend on the total number of funds managed by our sample funds' management companies. To the extent that future switching costs related to fund family size enter into investors' decisions, including this variable helps capture this influence.

\section{IV.1. Model-General Setup}

In the model, which extends the framework of Carlson and McAfee (1983), demand for sector funds is characterized by a continuum of investors searching over funds with varying attributes. Investors have heterogeneous search costs, and we also allow for the fact that some index funds are "easier to find" than others, by allowing for heterogeneous sampling probabilities over each fund. We assume that fund attributes are vertical characteristics, and that all investors share a common utility function. Thus conditional on investing in fund $j$, an investor receives indirect utility equal to $u_{j}\left(W_{j} ; \theta\right)$, where $W_{j}$ is a vector of fund attributes and $\theta$ is a set of parameters that characterize how the attributes affect utility. ${ }^{19}$ The model requires few

\footnotetext{
${ }^{18}$ Patterns in average fund prices within entering and incumbent fund families may also manifest switching cost effects, but these are beyond the scope of this paper. We hope to address this in future research.

${ }^{19}$ We have explored allowing a more general preference specification that incorporates horizontal taste differences across consumers; i.e., where the conditional indirect utility of fund $\mathrm{j}$ is now specific to a particular consumer $\mathrm{i}$ : $u_{j i}\left(W_{j} ; \theta_{i}\right)$. However, we have not yet been able to demonstrate that market outcomes driven by horizontal differentiation are identifiably separable in our data from those caused by across-consumer variation in search costs. We allow for now the idiosyncratic portion of consumer purchase behavior to be explained by search, and later compare the ability of this model to fit the data with that of a model without search but with horizontal taste shifters.
} 
specific assumptions on the form of $u_{j}(\cdot)$ a priori. However, for reasons that will become clear later, we assume here that utility is a linear function of fund characteristics:

$$
u_{j}=\underline{W}_{j} \beta-p_{j}+\xi_{j},
$$

where $\underline{W}_{j}$ are the elements of $W_{j}$ other than price $p_{j}$ and an unobservable component $\xi_{j}$. Note that the coefficient on the price term has been normalized to -1 , so utilities are expressed in terms of the unit of price measurement. Here, given the nature of the good, that unit is basis points. Thus one can think of $u_{j}$ as specifying fund utility per dollar of assets the investor holds in it.

Given these preferences, the fund delivering the largest $u_{j}$ would gain $100 \%$ market share if search were costless. However, because search is costly in our framework, market shares are distributed across funds. We assume search costs are heterogeneous in the investor population and have distribution $G(c)$. Investors incur their particular search cost whenever they wish to find out the indirect utility offered by a particular fund, with the exception of the first fund they search (this assures all investors desiring to hold assets in the sector end up doing so regardless of their search cost level). For tractability, we assume that investors search with replacement, and are allowed to "revisit" previously searched funds. ${ }^{20}$ We also restrict investors to only purchase shares in one S\&P 500 index fund.

Define investors' belief about the distribution of funds' indirect utilities $H(u)$. Then the optimal search rule for an investor with search $\operatorname{cost} c_{i}$ is to search for another fund as long as

$$
c_{i} \leq \int_{u^{*}}^{\bar{u}}\left(u-u^{*}\right) d H(u),
$$

where $\bar{u}$ is the upper bound of $H(u)$, and $u^{*}$ is the indirect utility of the highest-utility fund searched to that point. This is a standard condition in sequential search models; search continues if the marginal cost of search is no greater than the expected marginal benefit. We simplify matters by assuming that investors observe the empirical cumulative distribution function of funds' utilities. That is, label the $N$ funds by ascending indirect utility order, $u_{1}<\ldots<u_{N}$. Then

$$
H(u)=\frac{1}{N} \sum_{j=1}^{N} \mathrm{I}\left[u_{j} \leq u\right] .
$$

\footnotetext{
${ }^{20}$ The search-with-replacement assumption simplifies matters in search models involving a finite number of (as opposed to continuum of) products because we do not need to worry about how investors' beliefs about $H(u)$ evolve as certain funds are removed from consideration. This deviation from reality is small when there are a large number of funds. The revisit assumption implies of course that the investor's benefit from searching is relative to the best fund yet searched, rather than the particular fund in hand at any given time.
} 
Thus investors know the available array of indirect utilities; they just do not know which fund provides what utility level until engaging in costly search.

The optimal search rule yields critical cut-off points in the search distribution, given by:

$$
c_{j}=\sum_{k=j}^{N} \rho_{k}\left(u_{k}-u_{j}\right),
$$

where $\rho_{k}$ is the probability that fund $k$ is sampled on each search (these probabilities are known by investors), and $c_{j}$ is the lowest possible search cost of any investor who purchases fund $j$ in equilibrium. The intuition behind this expression is as follows. Optimal search continues until the investor's expected benefit from searching is lower than the search cost. The right-hand side of expression (4) is the expected benefit of additional search for an investor who has already found fund $j$. This is product of the probability $\rho_{k}$ that another search yields a higher-utility fund (recall $u_{k}>u_{j}$ if $k>j$ ) and the corresponding utility gain $u_{k}-u_{j}$, summed over all funds superior to fund $j$. Fund draws with utilities less than $u_{j}$ are ignored in this calculation, as investors can costlessly revisit funds already searched. Note that this expected benefit declines in the fund's index (in fact, $c_{N}=0$ ). Thus as long as an investor's search cost is lower than $c_{j}$, he or she keeps searching until a fund offering greater utility than fund $j$ is found. On the other hand, more search is not worthwhile for any investor having found fund $j$ but with search costs greater than $c_{j} .{ }^{21}$ Note that this implies the product index is declining in the ordinal ranking of critical search cost values; i.e., while $u_{1}<\ldots<u_{N}, c_{N}<\ldots<c_{1}$.

We can use this optimal search behavior to identify elements of the search cost distribution. Funds' market shares can be written in terms of the search cost c.d.f. by using the search-cost cutoffs above. Consider the lowest-utility fund, $u_{1}$. This fund has a high critical search value, $c_{1}$, because the expected search benefit to any investor having already found this fund is large. Therefore only those investors with very high search costs $\left(c>c_{1}\right)$ purchase the fund; all others continue to search. At the same time, though, not all investors with $c>c_{1}$ purchase the fund; only those (unfortunate) ones who happen to draw fund 1 first - which happens with probability $\rho_{1}$. Thus the market share of the lowest-utility fund is

\footnotetext{
${ }^{21}$ It is interesting to note the links between the demand system implied by this framework and that implied by a standard discrete choice demand model, such as a multinomial logit. This model has purely vertically differentiated products, but still implies a nondegenerate market share distribution (even if all prices were equal), because the distribution of search costs across investors creates a type of horizontal differentiation. The standard logit model also introduces products that are (almost) purely vertically differentiated, but builds in horizontal differentiation (and its resulting market share dispersion) directly into the preference function with the i.i.d. random utility term.
} 


$$
q_{1}=\rho_{1}\left(1-G\left(c_{1}\right)\right)=\rho_{1}\left(1-G\left(\sum_{k=1}^{N} \rho_{k}\left(u_{k}-u_{1}\right)\right)\right) .
$$

Now consider the market share of the second-lowest utility fund, fund 2. Again a fraction of the highest-search-cost investors $\left(c>c_{1}\right)$, unable to afford a second search, find fund 2 first and purchase it. But a subset of investors with search costs $c_{1}<c<c_{2}$ also purchase fund 2; namely, those who find fund 2 on their first search, or those search only to find fund 1 and keep searching until they draw fund 2. The former case happens with probability $\rho_{2}$. The latter occurs with probability $\rho_{2} /\left(1-\rho_{1}\right){ }^{22}$ Thus the total market share of fund 2 is

$$
q_{2}=\rho_{2}\left(1-G\left(c_{1}\right)\right)+\frac{\rho_{2}}{1-\rho_{1}}\left[G\left(c_{1}\right)-G\left(c_{2}\right)\right]=\rho_{2}\left[1+\frac{\rho_{1} G\left(c_{1}\right)}{1-\rho_{1}}-\frac{G\left(c_{2}\right)}{1-\rho_{1}}\right] .
$$

Analogous calculations, detailed in the appendix, produce a generalized market share equation for funds 3 through $N$ :

$$
q_{j}=\rho_{j}\left[\begin{array}{l}
1+\frac{\rho_{1} G\left(c_{1}\right)}{1-\rho_{1}}+\frac{\rho_{2} G\left(c_{2}\right)}{\left(1-\rho_{1}\right)\left(1-\rho_{1}-\rho_{2}\right)}+\sum_{k=3}^{j-1} \frac{\rho_{k} G\left(c_{k}\right)}{\left(1-\rho_{1}-\ldots-\rho_{k-1}\right)\left(1-\rho_{1}-\ldots-\rho_{k}\right)} \\
-\frac{G\left(c_{j}\right)}{\left(1-\rho_{1}-\ldots-\rho_{j-1}\right)}
\end{array}\right] .
$$

These equations form a system of linear equations linking $G\left(c_{1}\right), \ldots, G\left(c_{\mathrm{N}-1}\right)$ - the population fractions with search costs less than the distribution's critical values - to observed market shares. Moreover, we know $G\left(c_{\mathrm{N}}\right)=0$, because (4) implies $c_{N}=0$ and search costs cannot be negative. ${ }^{23}$

The market supply side is comprised of $F$ funds that choose prices to maximize current profits. Let $S$ be the total size of the market, $p_{j}$ and $m c_{j}$ be the price and (constant) marginal costs for fund $j$, and $q_{j}$ be the fund $j$ 's market share given the price and characteristics of all sector funds. Then the profits of fund $j$ are

$$
\Pi_{k}=S q_{j}(p, \underline{W})\left(p_{j}-m c_{j}\right) .
$$

Profit maximization implies the standard first-order condition for $p_{j}$ :

$$
q_{j}(p, \underline{W})+\left(p_{j}-m c_{j}\right) \frac{\partial q_{j}(p, \underline{W})}{\partial p_{j}}=0 .
$$

\footnotetext{
${ }^{22}$ The total probability that a search sequence yields only fund 1 draws until a fund 2 draw is $\rho_{1} \rho_{2}+\rho_{1} \rho_{1} \rho_{2}$ $+\rho_{1} \rho_{1} \rho_{1} \rho_{2}+\ldots=\rho_{1} \rho_{2} /\left(1-\rho_{1}\right)$. When summed with the probability that the first draw is fund $2\left(\rho_{2}\right)$, this yields $\rho_{2} /\left(1-\rho_{1}\right)$ as the probability that an investor with $c_{2}<c<c_{1}$ buys fund 2 .

${ }^{23}$ Notice that since $G\left(c_{N}\right)=0$, the market share equations only include $N-1$ values of $G(c)$.
} 
The elasticities $\partial q / \partial p$ faced by the fund are of course determined in part by the derivatives of the share equations (7). We show in the appendix that these derivatives are:

$$
\begin{gathered}
\frac{\partial q_{j}}{\partial p_{j}}=-\frac{\rho_{1} \rho_{j}^{2} g\left(c_{1}\right)}{1-\rho_{1}}-\frac{\rho_{2} \rho_{j}^{2} g\left(c_{2}\right)}{\left(1-\rho_{1}\right)\left(1-\rho_{1}-\rho_{2}\right)}-\sum_{k=3}^{j-1} \frac{\rho_{k} \rho_{j}^{2} g\left(c_{k}\right)}{\left(1-\rho_{1}-\ldots-\rho_{k-1}\right)\left(1-\rho_{1}-\ldots-\rho_{k}\right)} \\
-\frac{\rho_{j}\left(\sum_{k=j+1}^{N} \rho_{k}\right) g\left(c_{j}\right)}{\left(1-\rho_{1}-\ldots-\rho_{j-1}\right)}
\end{gathered}
$$

Note search cost distribution densities $g(c)$, evaluated at the cutoff values for funds offering lower utility than $j$ (i.e., $k<j$ ), affect fund $j$ 's demand elasticity. To see why, consider investors' reactions to an increase in the price of fund $j$. The price hike decreases $u_{j}$. This has two distinct effects on the critical search cost cutoff values. For $k<j, c_{k}$ decreases (see (4)); if you hold a fund of lower quality than $j$, additional search becomes less appealing when fund $j$ has its offered utility reduced. Thus some investors with search costs less than $c_{j-1}$ who would have formerly continued searching and serendipitously found fund $j$ no longer continue searching. Fund $j$ 's sales lost through this channel are directly related to the density of the investor population at these higher search costs, as embodied in the first $j-1$ terms of (11). The second, more direct quantity effect of a price increase is from the increase in $c_{j}$ when $u_{j}$ falls. That is, continued search becomes more beneficial for investors who would have purchased $j$ at the original price. Some investors on the margin now choose to continue searching and end up purchasing higher utility funds than $j$. The number of such marginal investors is embodied in $g\left(c_{j}\right)$. The final term in (11) captures this loss.

This link between fund prices and the p.d.f. of the search cost distribution, as well as the connections between market shares and the distribution's c.d.f. shown above, play an important role in empirically identifying the model. We discuss this below.

\section{IV.2. Model-Identification}

The market share equations (7) show how we can map from observed market shares to the c.d.f. of the search cost distribution evaluated at the critical values. If we know (or assume) the sampling probabilities $\rho_{j}$, then all $G\left(c_{j}\right)$ can be read off directly from market shares. Solving the linear system (7) to recover $G\left(c_{1}\right), \ldots, G\left(c_{\mathrm{N}-1}\right)$ and using the fact that $G\left(c_{N}\right)=0$ gives all 
critical values of the c.d.f. If the sampling probabilities are unknown, and must be estimated, the probabilities as well as the search cost distribution can be parameterized as $\rho\left(\omega_{1}\right)$ and $G\left(c ; \omega_{2}\right)$, respectively. Given $\omega_{1}$ and $\omega_{2}$ of small enough dimension, observed market shares can be used to estimate these parameters.

While market share data can be mapped into the c.d.f. of the search cost distribution, the actual distribution cannot in general be traced out using only share information. This is because market shares do not generically identify the level of the critical search cost values $c_{1}, \ldots, c_{N}$, only their relative positions in the distribution. However, shares $d o$ identify search cost levels in the special but often-analyzed case of homogeneous (in all attributes but price) products with unit demands; i.e., when $u_{j}=u^{\prime}-p_{j}$, where $u^{\prime}$ is the common indirect utility delivered by the funds. In this case, (4) implies

$$
c_{j}=\sum_{k=j}^{N} \rho_{k}\left(u^{\prime}-p_{k}-\left(u^{\prime}-p_{j}\right)\right)=\sum_{k=j}^{N} \rho_{k}\left(p_{j}-p_{k}\right) .
$$

Now, given sampling probabilities (either known or parametrically estimated), $c_{1}, \ldots, c_{\mathrm{N}-1}$ can be calculated directly from observed fund prices using (12).

In the more general case where products differ in other attributes than price alone, additional information is required to identify cutoff search cost values. We find this information in fund companies' optimal pricing decisions. The logic of our approach is straightforward. We need to recover the p.d.f. of the search cost distribution (evaluated at the cutoff points). These values enter the derivatives of the market share equations with respect to price, (11). If we assume Bertrand-Nash competition, the first order conditions for prices (9) imply ${ }^{24}$ :

$$
\frac{\partial q_{j}(p)}{\partial p_{j}}=-\frac{q_{j}(p)}{p_{j}-m c_{j}} .
$$

Note that we observe prices and market shares in the data. Therefore, given knowledge of marginal costs $m c_{j}$, we can compute $\partial q_{j} / \partial p_{j}$ using the first-order condition (13). From (11), these derivatives form a linear system of $N-1$ equations that can be used to recover the values of the search cost density function $g(c)$ at the critical values $c_{1}, \ldots, c_{N-1}$. If marginal costs are not known,

\footnotetext{
${ }^{24}$ We discuss the second-order conditions in the appendix. We will also check below that firms' estimated profit functions do not have global maxima different from those implied by the first-order conditions.
} 
they can be parameterized along with the search cost distribution and estimated from the price and market share data.

Once both the values of the search cost c.d.f. and p.d.f. (evaluated at the cutoff search costs) have been identified, we can recover the level of these cutoff search $\operatorname{costs} c_{j}$ in the general case of heterogeneous products. To do so, we note that by definition the difference between the c.d.f. evaluated at two points is the integral of the p.d.f. over that span of search costs. This difference can be approximated using the trapezoid method; i.e.,

$$
G\left(c_{j-1}\right)-G\left(c_{j}\right)=0.5\left[g\left(c_{j-1}\right)+g\left(c_{j}\right)\right)\left(c_{j-1}-c_{j}\right)
$$

We invert this equation to express the differences between critical search cost values in terms of the c.d.f. and p.d.f. evaluated at those points:

$$
c_{j-1}-c_{j}=\frac{2\left[G\left(c_{j-1}\right)-G\left(c_{j}\right)\right\rfloor}{g\left(c_{j-1}\right)+g\left(c_{j}\right)}
$$

Given the critical values of $G(c)$ and $g(c)$ obtained from the data above, we can recover the $c_{j}$, and from these trace out the search cost distribution. ${ }^{25}$ In non-parametric specifications, a normalization is required: the demand elasticity equations do not identify $g\left(c_{N}\right)$, so a value must be chosen for the density at zero-search costs (recall that $c_{N}=0$ ). ${ }^{26}$

Finally, we can also use the critical values of the search cost distribution to estimate the indirect utility function (1). The implied indirect utilities of the funds $u_{j}$ are derived from the cutoff search costs via the linear system (4) above. ${ }^{27}$ We regress the sum of these values and the respective fund's price (because of the imposed unit price coefficient) on the observable characteristics of the fund to recover $\beta$, the weights of the characteristics in the indirect utility function. We must be careful, however, as the unobservable components $\xi$ are likely to be correlated with price, which would result in biased coefficients in ordinary least squares

\footnotetext{
${ }^{25}$ Of course, since we only identify the search cost distribution at the cutoff values $c_{j}$, we don't identify the c.d.f through its entire domain. Any monotonically increasing function between the identified cutoff points could be consistent with the true distribution; our trapezoid approximation essentially assumes this is linear. The approximated c.d.f. converges to the true function as the number of funds increases.

${ }^{26}$ The intuition for this is that demand elasticities are determined by the actions of searchers on the margin between two funds. Given that search is responsible for spreading output shares across funds, and that changes in indirect utilities move shares on the margin only between adjacent funds, there are only $N-1$ margins for $N$ funds. Thus the markup/elasticity equation system only identifies the first $N-1$ cutoff values of the search cost density function.

${ }^{27}$ Note that in our current setup, (4) implies that $u_{1}=0$, so fund utility levels are expressed relative to the least desirable fund. This normalization results from our assumption that all investors purchase a fund; if we added an outside good that could be purchased without incurring a search cost, we could alternatively normalize the utility of this good to zero.
} 
regressions. We use instrumental variables in an attempt to avoid this problem.

\section{V.1. Estimation-The Basic Model}

Our approach to estimating the model is to build up from the simplest version of the model, adding complexities (sometimes at the cost of parametric assumptions) as we go along, and compare the performance of the various versions in explaining the data. This both builds intuition for the reader regarding the effect of the various assumptions involved in the modeling process as well as, we hope, argues for the importance of considering departures from standard modeling frameworks.

We begin by assuming that funds are homogeneous: the only characteristic that matters to S\&P 500 index fund investors is price. As noted above, homogeneity implies that $u_{j}=u^{\prime}-p_{j}$, where $u^{\prime}$ is common to all funds, and given sampling probabilities, the cutoff search cost values can be computed directly from observed prices.

Consider the case where funds have equal sampling probabilities; i.e., $\rho_{j}=1 / N \forall j$. In this case the market share equations (7) simplify to:

$$
q_{j}=\frac{1}{N}+\sum_{k=1}^{j-1} \frac{1}{(N-k+1)(N-k)} G\left(c_{k}\right)-\frac{1}{(N-j+1)} G\left(c_{j}\right) .
$$

As noted above, this system non-parametrically identifies the c.d.f. of the search cost distribution. The implied $G\left(c_{j}\right)$ values, when combined with the computed $c_{j}$ from the version of (4) with $\rho_{j}=1 / N \forall j$ and $u_{j}=u^{\prime}-p_{j}$, would allow us to trace out the search cost distribution.

However, this simple version of the model is rejected straightaway by the data. To see why, note that when sampling probabilities are equal and funds homogeneous, there will be a negative and monotonic relationship between price and market share. ${ }^{28}$ A glance at Figure 6, which plots the fund price vs. market share (both in logs) for the 2000 funds, shows that this is not the case in the sector. ${ }^{29}$ While there is a clear negative correlation between price and market

\footnotetext{
${ }^{28}$ There is a conceptual issue regarding whether market shares should be measured as asset (stock-based) shares or gross-inflow (flow-based) shares. We primarily use asset shares in this paper, in part because precise gross flows cannot be computed (see the discussion in the data appendix). However, our approximate gross inflow measure yields market shares that are highly correlated $(\rho=0.93)$ with the asset-based measure. We found similar results in specifications estimated with both flow-based and asset-based shares; see below.

${ }^{29}$ Other years show similar patterns; we chose 2000 because it had the largest number of funds.
} 
share, the relationship is far from monotonic. (Recall as an example of this departure from monotonicity that the highest-fee fund was the $10^{\text {th }}$-largest of the over 85 funds in 2000.)

The rejection of this simplest version of the model indicates that fund differentiation must matter on some level. We consider two possibilities. One is that funds are perceived by investors as homogeneous, but the likelihood of "finding" a fund is a function of the fund's attributes. This breaks the basic model's implication of monotonicity between fund price and market share by letting certain higher-priced funds be sampled with a higher relative probability than some of their lower-priced competitors. The second possibility, already alluded to above, is that investors view funds as differentiated in non-price characteristics. A higher-priced fund may then have a larger market share than its cheaper competitor because it provides other attributes investors value. We consider both of these more complex versions in turn.

\section{V.2. Estimation-Unequal Sampling Probabilities}

To allow sampling probabilities $\rho_{j}$ to vary across funds, we use the following functional for specification:

$$
\rho_{j}=\frac{Z_{j}^{\alpha}}{\sum_{k=1}^{N} Z_{k}^{\alpha}},
$$

where $Z_{j}$ is an index of fund level observables that influence the probability that the fund sampled. The parameter $\alpha$ captures any nonlinearities. What should enter into $Z_{j}$ ? If sampling probabilities do differ, they are likely correlated with a fund's marketplace exposure. Since the modeled search process stylizes a very complex process where investors learn about and choose among alternative funds, it may be reasonable to assume certain funds have more visibility than others and are thus more likely to be considered by investors. One possible exposure measure is advertising expenditures. Unfortunately, we do not observe this at the fund level. ${ }^{30}$ Reasonable proxies would be variables related to (but not completely collinear with) the size of the fund, to capture the dynamics of the search process and possible "social learning" effects. We use fund

\footnotetext{
${ }^{30}$ Some studies (e.g., Sirri and Tufano 1998) have used 12b-1 fees and load charges - which we do observe - to proxy for advertising and marketing expenditures. This is not a particularly strong proxy for our purposes, as many funds advertise despite not charging either $12 \mathrm{~b}-1$ fees or loads, and funds that do charge such fees may well spend a considerably different amount on advertising from the actual levels of the charges. Of particular trouble for our methodology are the former group of funds: the 12b-1/load advertising proxy would imply a large number of funds that did not advertise, and it is not clear what the sampling probability would be in such cases.
} 
age to embody these influences in our benchmark $Z_{j}$ and then consider extensions below.

We estimate the search cost distribution and sampling probabilities using the market share equations (7) and the first-order pricing conditions (9) by nonlinear least squares. Search costs are parameterized as lognormal with $\mathrm{E}[\ln (c)]=\mu$ and $\operatorname{Var}[\ln (c)]=\sigma^{2} \cdot{ }^{31}$ We add further flexibility by allowing both of these moments to have trends over the sample. The mean marginal cost and the sampling probability parameter(s) are also estimated.

The results are presented in Table 5. Five slightly different versions are estimated. The benchmark model, in column (A), uses the asset-based market shares and literature-standard prices upon which the empirical work above is based. A version that uses flow-based market shares discussed previously is also estimated; the results are in column (B). The two versions (C) and (D) explicitly account for possible price incidence differences between load and no-load funds. While the annualized prices of no-load funds are invariant to the investor's holding period (since they charge only asset-based annual fees), annualized costs for load fund investors depend on how long assets are held. For example, annualized costs for a typical front-end load fund are highest for redemptions made in the purchase year because of the high up-front charge, but decline with each year the assets are held. Almost invariably, for multiple-share-class loaded portfolios, front-load (A-shares, in industry parlance) funds have the lowest annualized costs in the long run. However, this is not always the case for a seven-year holding period as assumed in the standard price measure. We therefore estimate a version based on 10-year-holding-period annualized prices — where A shares are the lowest cost—and restrict the choice set to only noload and front-load funds. The results of this specification are in column (D). Column (C) presents for comparison purposes a version using the same restricted product set but with the standard price measure. The purpose of these specifications is to see if our results are affected by any price mismeasurement for load-fund investors arising from our inability to measure expected holding periods. In the specification of column (E), we allow $Z_{j}$ to be a linear combination of both the fund's age and the logged number of funds managed by the funds' management company. (The age coefficient is normalized to one and an estimated coefficient $\gamma$ multiplies the logged number of funds.) The intent is to account for the possibility that some

\footnotetext{
${ }^{31}$ A lognormal specification fit the data much better than normal, exponential, uniform, and gamma distributions. We show below that a lognormal distribution also fits nonparametric estimates of the search cost distribution well. The "errors" in our estimating equations can be interpreted as measurement errors in marginal costs and computed market shares.
} 
investors consider S\&P 500 index funds while already holding assets in non-sector funds. If investors are more likely to purchase sector funds already in the same fund family as the funds which they already own (say because of switching costs as discussed above), including a measure of the size of the fund family in the search probability is a way to proxy for this effect.

Observe first that the parsimoniously parameterized model explains both price and market share extremely well. In our benchmark model, we explain $92 \%$ of price variation and $98 \%$ of the variation in market shares. The corresponding values for the other specifications are also high. Notice, too, that the estimates' qualitative features are consistent across the specifications. There is little quantitative difference in the estimates either, with the possible exception of the specification using flow-based market shares.

A few patterns regarding the search cost distribution are evident in the results. The estimated search costs appear reasonably sized. Furthermore, the mean logged search cost is trending downward throughout the sample period while at the same time variance is increasing. We shall return to this result in detail below. The benchmark results imply a median search cost of 5 basis points (a $\$ 5$ search cost per $\$ 10,000$ of assets invested) in 2000, down from 21 basis points in 1996. There is considerable heterogeneity in search costs across the population, and the distribution is highly skewed; the $25^{\text {th }}$ - and $75^{\text {th }}$-percentile search costs are 0.7 and 75 basis points, respectively. The flow-based market share specification implies lower search cost levels, but exhibits the same trends. It does not appear that price mismeasurement for load-fund investors is greatly influencing the results.

Our estimates imply asymmetries in fund-sampling probabilities. The benchmark estimate of $\alpha$ is 2.6, indicating that fund age increases market exposure positively and nonlinearly. This is supported in the data: there are 11 pairs and 8 triples of funds with equal prices and unequal ages in our sample, and the older (oldest) fund has the largest market share in 8 of the pairs and 6 of the triples. In model (E), where the sampling probability is a function of both fund age and the number of funds run by its management company, $\gamma$ is positive and significant. Ceteris paribus, then, sector funds in larger fund families are more likely to be found (and purchased) by investors. ${ }^{32}$ We return to this point below. The estimated marginal costs for

\footnotetext{
${ }^{32}$ We have also estimated specifications (not reported here) where, besides age, the fund's distribution channelwhether it is a load or no-load fund - can also affect its sampling probability. Since load funds are sold through brokers rather than directly to investors, we thought it possible that the two types of funds might have systematically
} 
fund companies are small; the benchmark estimate of the mean is 4 basis points. The 12-basispoint estimate from the flow-based market share specification is considerably higher.

\section{V.3. Estimation-Heterogeneous Funds}

Freeing up sampling probabilities allows the model to fit the data quite successfully, and produces what are in our opinion economically sensible results. However, an alternative explanation for very different market shares among similarly priced funds is that they might simply be different products. To incorporate non-price differentiation into the model, we assume again that sampling probabilities are equal and funds share a common marginal cost. ${ }^{33}$ As shown above, the search cost distribution as well as fund utilities $u_{j}$ are nonparametrically identified in this case. We use the observed fund market shares and prices to trace out the implied search cost distribution for each sample year using the procedure discussed in Section III.2. The marginal costs of the funds are assumed identical at 10 basis points (i.e. it costs $\$ 10$ to administer an additional $\$ 10,000$ in assets). Experimenting with marginal costs as large as 30 basis points and as low as 0 basis points yielded similar findings.

Implied Search Costs. Table 6 contains the results of this exercise and reveals some interesting features of the implied search cost distributions. In the early part of the observation period, the upper percentiles of the search cost distribution are trending down (or in the case of the $99^{\text {th }}$ percentile, staying roughly constant). This trend continues throughout for the $75^{\text {th }}$ percentile. However, it is reversed after 1997 for the $90^{\text {th }}, 95^{\text {th }}$, and $99^{\text {th }}$ percentiles, which all rise substantially through 1999, until falling again in 2000. Thus it appears that while search costs have been falling for a substantial fraction of investors, they have actually been rising at the upper reaches of the distribution. ${ }^{34}$

different sampling likelihoods. We found that the estimated load coefficient was economically small and its inclusion barely changed the estimate of $\alpha$.

${ }^{33}$ In reality, funds are likely to both be differentiated and have different sampling probabilities. However, as evident from our discussion of identification, it is not possible to identify both effects separately using data on prices and market shares only. We must therefore investigate each possibility in isolation.

${ }^{34}$ Note that we do not report any results for quantiles lower than $50 \%$ in some years. The current framework implies the highest market share fund (Vanguard) offers the highest utility, and that the bulk of this market share is comprised of low-search-cost investors. Since we can only identify discrete cut-off points on the search cost distribution, and since Vanguard's market share was above $50 \%$ in all the years in our sample, our data yields little information about the lower tail of the search cost distribution. That is, any inference regarding the lower tail of the 
These patterns are more visible if one interpolates our estimated quantiles of the search cost distribution by fitting a parametric distribution. We plot in Figure 7 the nonparametrically identified search cost quantiles for 1996 and 2000 alongside log-normal distributions fitted to these quantiles using a least-squares criterion (only two years are plotted to ease clutter). Doing so highlights a considerable decline in search costs for investors below the $85^{\text {th }}$ percentile. For example, the interpolated median search cost in 1996 is 1.5 basis points, while the 2000 median is 0.2 basis points. Over the same period, however, search costs appear to have diverged across the population: the high end of the distribution saw increases in search costs. Notice that these results are consistent with those from the unequal-sampling-probabilities specification above. There, the logged search cost distribution had a falling mean but an increasing variance over the period. Calculating the search cost levels implied by that specification indicates that search costs at the far end of the distribution actually increased despite the falling mean, much as the pattern seen here in the differentiated-product model. (Although the earlier results imply increases only above the $97^{\text {th }}$ percentile, rather than the $85^{\text {th }}$, as is the case here.)

This across-investor divergence in search costs is concurrent with three events in the industry. First, the sector saw massive asset inflows during the period, as did equity mutual funds in general. The second was an influx of novice mutual fund investors. Figures from the Investment Company Institute (various issues, 1996-2000) indicate that participation in the mutual fund markets rose one-third between 1996 and 2000, from 37.2\% of households holding at least one fund to $49 \%$. These novice participants were likely less financially savvy than the average incumbent investor, and as a result they incurred higher costs (in time and/or effort) gathering the requisite information to guide their purchase decision. This composition shift may be driving in part our finding of increased search costs in the upper tail of the distribution. ${ }^{35}$

The third concurrent event was, as discussed earlier, considerable entry of high-priced S\&P 500 index funds (and the concomitant growth in the high-price segment of the sector). We interpret the increases at the upper end of the search cost distribution and the rise in market participation rates as suggestive evidence that the observed market share shift toward higher-

search cost distribution depends on functional form assumptions. As a result, we choose not to report any corresponding values here. However, we have much more information regarding the higher quantiles of the search cost distribution that is not dependent on any assumed function form for the distribution.

${ }^{35}$ The fact that overall Internet use among mutual fund investors grew during the same period (from $62 \%$ of mutual fund investors in 1998 to $68 \%$ of investors in 2000 - the only two years for which we have data) may account for part of the decreases seen in the bulk of the distribution. 
price funds may have been driven by the entry of novice mutual fund investors, with significantly higher search costs than prior investors, into the market. ${ }^{36}$ This is consistent with some of the curious features of the S\&P 500 index fund sector discussed above, and may perhaps also explain certain features of the mutual fund industry as a whole. This implication of our model is only suggestive - we would need investor-level data to test this notion definitively — but we do find the story tantalizing.

Checking first-order pricing conditions. Our estimation procedure relies on the fact that the prices given by firms' optimal pricing first-order conditions (13) are profit maximizing. The second-order conditions required for this to be true depend on the specific shape of the search cost distribution, and cannot be shown to hold unambiguously. These conditions are discussed in the appendix. To rule out possible deviations from profit maximization (both local and global), we investigate the "best-response" profit maximization problems implied by the estimated parameters of our model. If the pricing conditions are indeed optimal, we should expect to see that the prices implied by the model are close to the observed prices. Particularly challenging for the model is to explain why Vanguard is priced so low while the Morgan Stanley Dean Witter fund, which still has the $10^{\text {th }}$-largest market share, is priced so high. We calculate the profit functions for both below.

Figure 8 plots the calculated profits for Vanguard in 2000 as a function of the price it charges, assuming a marginal cost of 10 basis points. ${ }^{37}$ We hold the non-price utilities of all funds constant as Vanguard's price changes. The model implies a global profit maximum at a price of 25 basis points, 7 basis points above the observed 18 basis point fee charged in 2000 . Since small changes in the lognormal search cost distribution can play large roles in the implied demand elasticity, we believe this deviation between implied and observed prices is not large.

We repeat the same exercise for Morgan Stanley Dean Witter, which charged 268 basis points for its Class B index fund. The results are presented in Figures $9 \mathrm{a}$ and $9 \mathrm{~b}$. Observe that

\footnotetext{
${ }^{36}$ Novice investors may be more likely to desire the services of a financial advisor, which comes bundled with load funds, when making their fund purchase. We pursue this possibility further below by extending our framework to include the possibility of investors choosing a priori whether or not to purchase a load fund, and then choosing among only those funds with or without loads as determined by their initial decision of whether to purchase advice.

${ }^{37}$ Since calculation of the profit function requires knowledge of the search cost distribution away from the quantiles we identified using market share cutoffs, we use a lognormal approximation of the search cost distribution here, where the quantiles of the log-normal are fitted using nonlinear least squares to the quantiles implied by the data.
} 
MSDW's profit function peaks around 230 basis points. Again, this is not far from its observed price. The implied level of profits in this case is huge; if we instead allow a (very high) 200 basis point marginal cost, the implied profit of Morgan Stanley is still comparable to that of Vanguard, which holds 40 times more assets!

The search model appears to be implying reasonable profit-maximization conditions. We have estimated profit functions for other funds and found similar results. In particular, we have found that for funds with similar prices but very different market shares, the model implies similar optimal prices. This gives us additional confidence in our specification.

Fund Attributes Valued by Investors. We now use the fund utility values $u_{j}$ (calculated from the critical search cost values using (4)) to infer the contribution of funds' observable characteristics to investor utility. We assume a linear functional form (1) for the indirect utility function, both to keep things computationally simple and to stay consistent with the bulk of the discrete-choice literature. Since we impose that the coefficient on price in the $u$ function is -1 , we run the following regression to recover an estimate of $\beta$ :

$$
u_{j t}+p_{j t}=X_{j t} \beta+\eta_{j t}
$$

where $u_{j t}$ is the indirect utility of fund $j$ in year $t$ calculated from (4), $p_{j t}$ is the observed price of the fund, $X_{j t}$ are observed fund characteristics, and $\eta_{j t}$ is an error term that includes the unobservable attribute $\xi_{j t}$.

We include ten attributes in $X_{j t}$. There are dummies indicating whether a fund charges a load, and if it is a rear or deferred load. Loads are a pricing element (which we have already amortized into the price measure), but they also indicate funds sold with bundled broker services that investors may value. Rear or deferred loads indicate the presence of formal switching costs to removing assets from the fund. We also include a dummy if the fund is an exchange-traded fund (i.e., SPDRs or Barclay's iShares) to control for the special features of ETFs. We measure the number of additional share classes attached to the fund's portfolio (for a single-share-class fund this value is zero). The number of other funds managed by the same management company is included to capture any value from being associated with a large fund family. Fund age is in the regressions as well. ${ }^{38}$ (Here, both the number of family funds and age enter in logs to

\footnotetext{
${ }^{38}$ Because $\xi_{j}$ - which is included in $\eta_{j}$-is likely to be correlated with fund age (funds with higher levels of desired unobservable attributes are more likely to survive), we estimate (18) using instrumental variables. We use the
} 
parsimoniously embody diminishing marginal effects.) We add the current fund manager's tenure, measured in years, as a covariate (tenure can vary independently of fund age because of manager changes). And while all of the funds in our sample seek to match the return profile of the S\&P 500 index, they do exhibit some small differences in their financial characteristics. These can result from skilled trading activities by a fund's management despite having a severely constrained portfolio. We thus include measures of tax exposure (the taxable distributions yield rate), the yearly average of the ratio of monthly fund returns to those of the S\&P 500 index, and the standard deviation of monthly returns. To the extent that fund buyers prefer any persistent positive variations in financial performance, these controls should capture much of this effect. ${ }^{39}$

The utility function results are presented in Table 7. The results are qualitatively sensible. The coefficient on the exchange-traded fund dummy is positive and significant, as are the number of funds managed by the same company and fund age. Furthermore, higher tax exposure affects utility negatively and significantly. The number of other share classes sharing a common portfolio, as well as the fund-S\&P 500 index return ratio have positive coefficients, although these impacts cannot be statistically distinguished from zero. These characteristics all enter the estimated utility function in the expected direction. The most puzzling result is that the standard deviation of monthly returns coefficient is positive and significantly so. Ceteris paribus, investors should prefer a fund with less return volatility, not greater.

The coefficients on the "load" variables deserve further attention. The any load dummy is insignificant, suggesting that bundled advice is not a vertical component of utility; i.e., an attribute that all investors value. (We consider the possibility that there are horizontal preferences for such advice below.) The rear/deferred load dummy enters positively. Given that it indicates barriers to asset withdrawals, this is unusual. However, revisiting the above

\footnotetext{
instruments suggested by Berry, Levinsohn, and Pakes (1995): own-product attributes (to instrument for themselves in the demand equation) as well as summary measures (average levels) of the attributes of two sets of the other products in the sector: those produced by the same company and those produced by competitors.

${ }^{39}$ We also collected in a phone survey measures of funds' account service quality. These measures include the number of account statements per year, the fraction of the day account access by phone is available, a dummy indicating whether investors are able to write checks out of their fund balances, and a dummy indicating whether the fund provides phone access to financial advisers. We choose not to include these variables in our reported specifications because we were unfortunately unable to obtain historical account service data. However, when we estimated a utility function that included these measures a slightly smaller sample, we found that the number of statements and the availability of phone advisers had no significant measured utility effect, and that more account access by phone entered positively and significantly. The coefficient on check-writing privileges was negative and significant, strangely. Including these service measures did not greatly change the qualitative or quantitative utility impacts of the other attributes, which are discussed below.
} 
discussion on identification suggests an interpretation. Funds' indirect utility estimates are identified in part by market shares; the model explains the relatively large market shares of certain high priced funds by attributing to them a high utility level. The positive rear/deferred dummy suggests that such funds have larger market shares than is implied by their other attributes. But since these funds have built-in switching costs, this is perhaps not a surprise; some of their assets remain in the fund not because they have other favorable attributes, but simply because it would be costly for the investor to remove them. As such, this estimate is evidence of switching costs effects in the sector, at least for certain funds.

Horizontal Variation by Distribution Channel. Product differentiation in the model above is limited to the vertical dimension. Here, we briefly consider a specification that allows for a form of horizontal differentiation that is of particular interest given the institutional setup of the industry. Investors in this specification differ by type in terms of their preferred distribution channel; i.e., a fraction prefer to purchase load funds through a broker and the remainder buy noload funds directly. The fraction of each type in the investor population is simply the share of assets held in each type of fund. Those preferring to buy through a broker grew throughout the sample; the load funds' market share increased from 13\% in 1995 to over $20 \%$ in 2000.

We allow full flexibility across the two groups' search cost distributions. Estimation proceeds as before, except search costs are estimated for investors preferring each purchase channel separately, using only those funds in the respective channel. Figure 10 plots the search cost distributions for both investor groups in 1996 and 2000, which are particularly illustrative and comparable to earlier results. As can be seen, the search costs of no-load fund investors are lower than their counterparts who buy load funds. This is perhaps not surprising; investors who prefer the advice and services of a broker are likely to have higher information-gathering costs in financial matters. Very interestingly, it is also apparent that while search costs decreased over the sample for nearly all of the no-load fund investors, they increased for the top $40 \%$ of loadfund investors. This echoes our findings above of an upwards shift at the high end of the search cost distribution. Before, of course, we had considered both load and no-load buyers as a single investor type. The decomposition here indicates that this shift may be driven primarily by load fund investors. If it occurred because of the entry of novice investors into the market, as was supposed earlier, these results suggest that these new investors entered disproportionately into 
broker-sold funds. This strikes us as a sensible implication; financial neophytes would seemingly be more likely to be willing to pay for brokers' advisory services. Further bolstering this notion is the fact that most of the entry and market share gains at the high end of the price distribution (as discussed previously) was accounted for by load funds.

\section{Welfare Implications}

We take the model's ability to explain several features of the data and to provide seemingly sensible utility function weights and search costs estimates as being indicative of the importance of product differentiation and search in the retail S\&P 500 index fund market. In this section, we ask if, given our estimates, the competitive equilibrium results in there being too many funds from a social welfare standpoint. Since most financial portfolio needs could be met by a single S\&P 500 index fund, it is conceivable that having 85 funds serves only to induce losses of scale economies and wasteful search by investors.

Economists have long recognized that entry can be socially inefficient. Mankiw and Whinston (1986) formalize this notion in a model where entry creates a loss of scale economies due to the over-spreading of output across production units. Stiglitz (1987) and Stahl (1989), in theoretical exercises of particular relevance to our framework, highlight socially harmful effects on buyer search behavior as the number of market producers increases. They show that when search costs are heterogeneous across consumers, additional entry can increase the total consumer search costs incurred. Furthermore, entry in a search equilibrium can actually increase the market power of incumbents. This effect operates through the increased number of products reducing the probability of finding a lower price with each (costly) search, effectively lowering the demand elasticities facing producers. ${ }^{40}$

It is important to note that it is entirely possible for a free-entry (zero-profit) equilibrium to create a net social loss. Prospective entrants, when calculating whether entry into a market is privately worthwhile, do not fully internalize certain external effects that their entry may have (such as the loss of scale economies or induced search behavior of customers). The point at

\footnotetext{
${ }^{40}$ Of course, there are counterbalancing positive influences of entry on social welfare. Entry can reduce distortions of market power by increasing incumbents' demand elasticities, but this depends on the particulars of the search process. The second possible benefit of entry is through product variety, as analyzed in Dixit and Stiglitz (1977), among other places. If goods are heterogeneous and consumers differ in how they value product attributes, additional products can be welfare enhancing. We attempt to quantify this benefit in our welfare calculations.
} 
which the social return of an additional entrant falls to zero may come at a substantially lower number of producers than the number at which the marginal entrant's expected profits are zero.

To highlight the welfare implications of our estimates, we consider a polar case as a counterfactual: restricting entry into the sector to only one fund - the Vanguard 500 Index Fund. As mentioned above, it was the first entrant and is still the dominant player in the sector. While this counterfactual is perhaps not particularly realistic, the stark nature of the case serves to underscore the nature and size of the possible welfare impacts the many sector funds have had.

Search Losses. Welfare reductions from search come from two sources. One arises when investors end up purchasing funds that do not offer the highest indirect utility. The other loss is investors' direct expenditure of resources on search, which is the sum over all investors of the product of an investor's per-fund search cost and the number of funds searched before purchase. We compute both of these values for the retail S\&P 500 index fund market using our estimates.

The loss from ending up at a fund with lower utility ranking than $N$-i.e., the gain in utility that would occur of the fund with the highest utility value (Fund $N$ ) had 100\% market share-is easily calculated as the market-share-weighted utility difference:

$$
\operatorname{Loss}_{1}=\sum_{j=1}^{N} q_{j}\left(u_{N}-u_{j}\right)=u_{N}-\sum_{j=1}^{N} q_{j} u_{j},
$$

where the utility levels used in the calculation are those measured in the nonparametric specification above. These calculated losses are shown in the first numerical column of Table 10. The estimates fluctuate substantially in levels from year to year. However, as measured relative to $u_{N}$, the utility of the Vanguard fund, the loss is dropping throughout the period, from a high of $8.5 \%$ in 1995 to $2.5 \%$ in 2000 . This reflects in part the market share growth of the SPDRs. ${ }^{41}$ These costs are not huge — not surprising since the highest-utility fund holds a majority position - but at the same time are not trivial. As discussed below, given total sector assets, the estimated losses in dollar terms run into the several-hundred-millions.

The loss from direct search cost expenditures relative to those in the monopoly counterfactual are simply the total search expenditures in the observed free-entry equilibrium,

\footnotetext{
${ }^{41}$ As discussed previously, the sector also saw during this time a drop in the asset share of the lowest-priced funds and an increase in the share of high-price funds. Since low-cost SPDRs gained significant market share throughout the period, the overall shift to higher-priced funds was driven by asset movements from lower- to higher- priced funds within the upper quartiles of the distribution and market share losses by Vanguard.
} 
since no search is necessary with entry restricted to a single fund. To measure this, we must use parametric search cost distribution estimates rather than the nonparametric distributions recovered above. This is because we must take draws from our estimated search cost distribution in the computations. Our nonparametric identification scheme matches the critical values of the search cost distribution, but the portion of the distribution between is necessarily interpolated. Parameterizing the distribution smoothes this out in a reasonable way.

We re-estimate the heterogeneous fund model, but now impose a lognormal functional form on the search cost distribution. Figure 7 compares the estimated parametric distributions from this model with their nonparametric counterparts for 1996 and 2000 . Notice that the correspondence, both qualitatively and quantitatively, between the two versions is reasonable. This result makes us confident in going forward with computing the total welfare costs of search using the parametric search cost functions.

To calculate the expected loss for search, recall from above that an investor with search costs higher than $c_{1}$ will stop at the first fund. If investors sample funds evenly, $(N-1) / N$ of investors with search costs between $c_{1}$ and $c_{2}$ also stop at the first fund they sample. However, the fraction $1 / N$ among such investors who sampled the lowest utility fund on their first try will search again, incurring another search cost. Continuing on with this logic, the expected number of searches conducted by an investor with search $\operatorname{cost} c_{k+1}<c<c_{k}$ will be:

$$
E\left[n(c) \mid c_{k+1}<c<c_{k}\right]=\sum_{j=k+1}^{N} j p_{k, j} \prod_{l=0}^{j-1}\left(1-p_{k, l}\right)+k \prod_{l=0}^{k}\left(1-p_{k, l}\right)
$$

where

$$
p_{k, l}=\frac{N-k}{N-l} .
$$

Integrating incurred search costs over the population, the resulting consumer surplus lost in the observed equilibrium is given by:

$$
\operatorname{Loss}_{2}=\sum_{k=1}^{N} \int_{c_{k}}^{c_{k+1}} E[n(c)] c g(c) d c
$$

We evaluate the integral in (22) numerically, taking 100,000 draws from the search cost distribution. The two rightmost columns of Table 8 present the expenditures on search costs. The average number of funds searched by investors grew in conjunction with the number of funds in the sector, increasing over 2.5 times (from 9.3 to 24.8) from 1995 to 2000. However, 
total search expenditure did not rise; indeed, it dropped by nearly two-thirds. This is due to the fact that average search costs were falling throughout the period. As compared to the searchimposed loss from buying inferior funds, the direct search cost expenditures are somewhat smaller, typically $40-60 \%$ as large.

Additional Welfare Implications. We have ignored three other welfare implications of entry in the above analysis. First, even though products are differentiated, there is no product variety welfare loss above from restricting entry to Vanguard alone. This is because this fund already offers the highest indirect utility among all funds. This result is an artifact of assuming purely vertical differentiation. If in reality funds are also horizontally differentiated or if there are cross-sectional differences in investors' valuations of fund attributes, both distinct possibilities, then there may well be a product-variety welfare loss from restricting entry.

Second, entry can cause a loss of production scale economies when output is overspread across production units. If entrants steal market share from incumbents, they decrease the incumbent's output from its level in the absence of entry. If the production process embodies increasing returns to scale, this results in a socially costly reduction in average productivity levels. Restricting entry may thus hold an additional benefit of productivity gains.

Third, of course, is the effect that entry has on competition and the reduction of market power. Granting a monopoly (an unregulated one at least) could in all likelihood create greater distortions from market power.

We attempt to quantify product variety losses of monopoly by estimating a logit demand system to back out the implied welfare loss when entry is restricted. Assuming the demand system follows the standard assumptions of the logit model (see, e.g., Anderson, de Palma, and Thisse 1992), this method has the benefit of being computationally simple to implement. Moreover, the logit model has well-known biases that tend to make it overestimate the benefit of variety. ${ }^{42}$ Thus we can interpret the welfare estimates implied by the logit as an upper bound on the variety loss that can be compared to the gain from reduced search computed above.

Small and Rosen (1981) demonstrate that the compensating variation resulting from a

\footnotetext{
${ }^{42}$ One is the implication of a "pure variety" benefit. The logit demand system implies welfare gains even if entering products are exactly the same as incumbents in all respects but $\varepsilon_{i j}$, because additional products raise the expected value of $\max \left(\varepsilon_{i j}\right)$. Petrin (2002) contains a discussion of welfare measurement biases in standard logit models.
} 
change in the choice set in the logit model is

$$
\Delta e=-\frac{1}{\lambda}\left[\ln \sum_{j} \exp (\underline{\Gamma})\right]_{\underline{\Gamma}^{o}}^{\Gamma^{f}},
$$

where $\Delta e$ is the compensating variation for each consumer, $\lambda$ is the marginal utility of income (the price coefficient in the logit regression), $\underline{\Gamma}$ is the vector of mean product utilities $\delta_{j}$, and $\underline{\Gamma}^{o}$ and $\underline{\Gamma}^{f}$ are respectively the pre- and post-change values of $\underline{\Gamma}$. Since in our particular case prices are measured in basis points, so too will be the welfare measure. The total dollar value of the welfare change is this value multiplied by sector assets.

We calculate the implied product variety welfare benefit by first constructing mean utilities $\delta_{j}$, which can be shown (e.g., Anderson, de Palma, and Thisse 1992) to be simply the natural logarithm of the ratio of a fund's market share to that of the outside good. The $\delta_{j}$ are regressed on product attributes to obtain $\lambda$ and also used directly in $\underline{\Gamma}^{o}$ and $\underline{\Gamma}^{f}$ in (25). ${ }^{43}$ Table 9 reports these results. The upper panel reports the estimated utility weights. They are qualitatively similar to those we obtain above from our model. The attribute coefficients have the same signs in both models in all but one case, the most puzzling of the prior specification (the monthly return standard deviation). This attribute coefficient has the expected negative sign here. The lower panel contains implied welfare losses from reduced product variety when entry is restricted to Vanguard. The losses are smaller than the benefits gained from reduced search. They rise with the number of funds throughout the sample, from 8.8 basis points in 1995 to 23.1 in 2000. Much of this increase may be driven by the pure-variety benefit implication of the logit model, since there are many more funds at the end of the sample.

We now estimate potential social losses from the reduction in scale economies caused by the over-spreading output across the many funds. For a subsample of our data (approximately $80 \%$ of the fund-year observations), we have data on funds' total costs. These cost numbers were obtained from Lipper Analytical Services, who use funds' annual expense statements to compute costs as a share of the average net assets managed by the fund over the course of the year. We use this data to estimate a starkly simple cost function that yields an estimate of the

\footnotetext{
${ }^{43}$ We define total market size in a year as total assets in all growth and income funds, prorated by the share of retail S\&P 500 funds' assets in the all-S\&P 500-funds total. As above, $\delta_{j}$ includes the unobserved product attribute $\xi_{j}$, so we use instrumental variables estimation in the logit regression. The counterfactual $\underline{\Gamma}$ vector is comprised of only the $\delta_{j}$ for the Vanguard fund.
} 
fixed yearly operating cost of the fund. This cost function is linear in funds' total net assets; i.e.,

$$
C_{t}=F+m c \cdot T N A_{t} .
$$

That is, the total cost of operating a fund during a given year (i.e., "production" costs) are equal to a fixed cost $F$ plus the product of the fund's total net assets under management and a constant marginal cost $m c$. We assume both $F$ and $m c$ are constant over the time period of our sample.

While extremely simple, this specification offers an easily characterized welfare loss of entry through the loss of scale economies. The social cost of an additional fund is simply the fixed cost, because any assets can be shifted among funds at a the same marginal cost. If returns to scale in the industry were alternatively characterized by declining marginal costs, for example, this loss is much harder to measure, because it would then depend on how many assets are taken from which funds and those funds' initial assets levels. While clearly over-simplistic, we believe our simple functional form for costs is a reasonable first-order approximation.

The cost function estimates imply an annual fixed cost of $\$ 1.22$ million (s.e. $=\$ 0.16$ million) and a marginal cost of $\$ 0.00182$ per dollar of assets -18.2 basis points (s.e. $=0.1$ basis points). ${ }^{44}$ The coefficients are estimated fairly precisely, particularly for marginal cost, and the goodness of fit is high $\left(\mathrm{R}^{2}=0.98\right)$. Both coefficient estimates strike us as reasonable; the estimated marginal cost is less than most of the prices of funds in our sample, although surely in reality there is some variation in this value across funds. ${ }^{45}$

The total welfare cost of the loss of scale economies in our counterfactual case is simply the sum of the fixed costs of the extra funds. In 2000, for example, since there were 82 funds, 81 funds paid total fixed costs that were $\$ 98.8$ million above those incurred by a monopolist. ${ }^{46}$ In reality, it is likely that a single index fund with such a large amount of assets could run up against increasing marginal costs. This would of course result in a lower implied average

\footnotetext{
${ }^{44}$ This marginal cost estimate is larger than that found in Section V.2. To do a back-of-the envelope check, consider that the average mutual fund account (across all fund types, not just in our sector) in 1997 was just over $\$ 26,000$. The 18.2 basis point estimate then implies an average annual cost per account of around $\$ 47$, which is a bit higher than the estimated \$30-40 cost of administering an account (accounting services, printing statements, etc.) reported in The Economist (2002).

${ }^{45} \mathrm{We}$ checked the robustness of the cost function results by including fund fixed effects to remove the influence of any across-fund differences in fixed costs may have on the marginal cost estimate. Doing so resulted in a marginal cost estimate of 17.9 basis points (s.e. $=0.2$ b.p.). We also estimated a specification that allowed fixed costs to be different for funds that are part of a multiple share class portfolio, and found no significant difference.

${ }^{46} \mathrm{We}$ are ignoring here the small number of funds, quite small in terms of total assets, that we know existed in the sector but do not have complete data for. (There were 85 funds observed in operation during some time in 2000, for example.) If these other funds' fixed costs were included, the numbers would be slightly higher.
} 
productivity gain from reducing the number of funds. Our estimates should then be considered an upper bound.

Table 10 combines all of the estimated welfare effects. It shows, in both basis points and dollar values, the total welfare changes that would be induced by the imposition of a Vanguard monopoly. The estimates imply welfare benefits of restricting entry throughout the sample, with the welfare gain rising from 1995 to 1999 and falling back again in 2000. To put these values in the perspective of the prices investors face, we also calculate the increase in Vanguard's price that, once it was a monopolist, would leave the average investor indifferent between the observed market structure and the imposed monopoly. ${ }^{47}$ Considering that Vanguard's price is just under 20 basis points throughout our sample, the price changes required to make investors indifferent are substantial, suggesting that there may be nontrivial welfare benefits of imposing a monopoly.

These calculations come with a host of caveats. We have entirely ignored any losses that may arise due to the deadweight loss of monopoly (not to mention any transfer in surplus from the consumer to the producer if there are distributional concerns). These could well be quite large. While such market power losses could plausibly be avoided by regulating the monopolist, regulation induces its own well known welfare costs (rent-seeking, corruption, etc.) that might be themselves substantial. Also, the product variety welfare and fixed cost savings estimates were made using assumed functional forms that, while facilitating straightforward interpretation, at the same time result in estimates that should be considered bounds rather than point estimates. It is likely that the true welfare loss from less variety in the monopoly counterfactual is less than estimated, and the actual productivity increase that would obtain from restricting entry could well be smaller than the numbers above indicate. These in combination would tend to cancel each other out, so the net effect depends on the relative departure of the actual welfare impacts from their calculated bounds.

Given these cautionary notes, we are reluctant to prescribe policy based on our welfare findings. However, we see them as being within the bounds of reasonableness. As such they may offer guidance in thinking about the welfare impacts of search and product differentiation in the retail S\&P 500 index fund sector in particular and the mutual fund industry as a whole.

\footnotetext{
${ }^{47}$ We keep things simple here by assuming inelastic demand, so no assets would leave the sector in response to a price change.
} 


\section{Conclusions}

We have presented evidence that key features of the U.S. mutual fund industry are driven by factors beyond financial portfolio heterogeneity alone. We focus on an asset segment, retail S\&P 500 index funds, where all funds are characterized by nearly homogeneous return patterns. Despite the homogeneity, we find that this sector exhibits the fund proliferation and price dispersion patterns seen in the broader industry.

We consider a combination of non-financial fund differentiation and information/search frictions as explanations for these observations. We construct an equilibrium model where investors with heterogeneous search costs shop over differentiated funds, and these funds compete with each other in prices mindful of investors' search behavior. The model is estimated using data from funds in the retail S\&P 500 index fund sector, and the search costs necessary to sustain the observed price dispersion are found to be of reasonable magnitude. Indeed, the estimated search costs exhibit much less dispersion than the price variation they support. Standard models involving search alone, however, are rejected by the data. Differentiated funds, either in their marketplace exposure or in the vertical component of utility that they offer investors, are necessary to our results. We furthermore decompose the contribution of various fund attributes to investors' indirect utilities, and find qualitatively sensible utility weights.

Our estimated search cost distributions also shed light on sector developments over the course of our sample. We observe considerable entry of high-price funds into the sector accompanied by a concurrent shift in assets toward more expensive funds. This, despite the fact that technological improvements over the same period were probably lowering average information-gathering costs. The estimated search cost distributions offer an explanation for these seemingly divergent features. We find that while average search costs were declining, costs for those at the upper percentiles of the distribution actually tended to increase through our sample years. This widening of the distribution was concurrent with the well documented increase in households' first-time participation in the mutual fund market, suggesting novice investors with high information/search costs caused this shift of assets into higher-price funds and supported the high-fee entrants. This is further supported when we allow investors to be horizontally differentiated by their preferences over funds' distribution channels; i.e., no-load (direct sales) versus loaded (broker-sold) funds. While virtually all investors considering noload funds exclusively enjoyed decreases in search costs over the sample, the top $40 \%$ of the 
load fund investor distribution experienced search cost increases over the same period. This is consistent with the novice-investor composition shift occurring mainly in the load fund sector, a sensible implication if new investors place a higher value on the financial advisory services that come bundled with load funds.

We also consider the welfare implications that search costs and differentiated products pose when there are a large number of financially identical funds. We find that the total costs sunk into the search process, both directly and indirectly through investors purchasing lowerutility funds, are sizeable. These costs could be avoided by restricting entry into the sector to a monopolist fund. Of course, this could well cause welfare losses of its own due to the reduction in product variety and the deadweight loss from increased market power. On net, our rough calculations indicate that imposing monopoly might be socially beneficial. Given the myriad simplifying assumptions that are required in such calculations, however, we are reluctant to make any policy recommendations too strongly.

While we focus here on a particular mutual fund asset class to control for financial performance heterogeneity while highlighting the possible roles of search and non-portfolio product differentiation, we think our results also suggest at least partial explanations for the fund proliferation and large fee dispersion seen in the mutual fund industry as a whole. Much more work needs to be done, however, to fully characterize these impacts. 


\section{Computational Appendix}

\section{A. Market Share Equations}

The market share of a particular fund depends on the probabilities that investors with search costs less than or equal to its corresponding cutoff search cost value from (2) finds the fund before finding another fund with a critical value higher than their search costs.

More formally, consider an investor with search $\operatorname{cost} \hat{c}$. Then the probability that our investor ends up purchasing a particular fund $k$ is equal to either (a) zero if $c_{k}>\hat{c}$, since the investor will always keep searching upon drawing fund $k$, or (b) if $c_{k}<\hat{c}$, the probability that he draws $k$ before drawing any other fund with a critical value less than $\hat{c}$. The latter probability is equal to $\rho_{k}$ times the sum of the probabilities of draw sequences where all funds have $c_{k}<\hat{c}$. We can express these probabilities, and therefore the corresponding market share equations (7), compactly using combinatorics. We derive these equations below.

First, define $\hat{c}_{l}$ as the largest fund cutoff search cost value that is less than $\hat{c}$ :

$$
\hat{c}_{l} \equiv \max \left\{c_{j} \mid c_{j}<\hat{c}\right\} \text {, }
$$

An investor with search cost $\hat{c}$ will stop searching once a fund with $c_{j} \leq \hat{c}_{l}$ is drawn, because at this point the benefit of additional search is less than its cost. Consider drawing such a fund as a "success" event. Then the probability of $T$ failures (i.e., where all $T$ draws are of funds with $c_{j}>\hat{c}_{l}$ ) is equal to

$$
\sum_{\bar{a} \mid a_{1}+\cdots+a_{l}=T}\left[\frac{T !}{a_{1} ! \ldots a_{l} !} \rho_{1}^{a_{1}} \ldots \rho_{l}^{a_{l}}\right]
$$

where the $l$ subscript denotes the fund with $c_{j}=\hat{c}_{l}, \rho_{j}$ is the probability of sampling fund $j, a_{j}$ is the number of times that the fund is drawn in the sequence of $T$ draws, and the sum is taken over all combinations of the $a$ vector $\left[a_{l}, \ldots, a_{l}\right]$ that sum to $T$.

It is known from combinatorics theory that the above summation simplifies to $\left(\rho_{l}+\ldots+\rho_{l}\right)^{T}$. Therefore the probability that fund $k$ is chosen after T failures — that $k$ is the "success" draw-is $\rho_{k}\left(\rho_{l}+\ldots+\rho_{l}\right)^{T}$. This expression must be summed over values of $T$ (from $T=0$, an immediate success where $k$ is the first fund drawn, to $T=\infty$, the limit of possibility) to obtain the total probability that an investor with search cost $\hat{c}$ purchases fund $k$ (alternatively, the probability that $k$ is chosen given $c_{k} \leq \hat{c}_{l}$ ). That is,

$$
\operatorname{Pr}\left(\text { Fund } k \text { chosen } \mid c_{k} \leq \hat{c}_{l}\right)=\rho_{k} \sum_{T=0}^{\infty}\left(\rho_{1}+\ldots+\rho_{l}\right)^{T}=\frac{\rho_{k}}{1-\rho_{1}-\ldots-\rho_{l}}
$$

This is the probability (b) in the second paragraph above.

Of course, this probability depends on the value of $\hat{c}$, since this determines the particular value of $\rho_{l}$. Investors with differing search costs thus have various probabilities of finding a "success" in fund $k$. For example, the highest-search-cost investors (i.e., those with $\hat{c}>c_{1}$ ) have $\hat{c}_{l}=c_{1}$, so they only take one fund draw and purchase whichever fund find. Thus the contribution to fund $k$ 's market share from investors with search costs above $c_{1}$ is therefore $\rho_{k}\left[1-G\left(c_{1}\right)\right]$. Analogously, for all $k \geq 2$, the market share comprised of investors in the next-lower 
segment of the search cost distribution (between $c_{2}$ and $c_{1}$ ) are those investors with that only draw fund 1 until fund $k$ is chosen. This market share is then $\left[G\left(c_{1}\right)-G\left(c_{2}\right)\right] \rho_{k} /\left(1-\rho_{1}\right)$. These are the values discussed in the text for $k=2$.

This is easily generalized. Investors with search costs between $c_{3}$ and $c_{2}$ purchase $k$ if $k \geq 3$ and if $k$ is the first fund drawn besides fund 1 or 2 . Thus their contribution to the market share of fund $k$ is $\left[G\left(c_{2}\right)-G\left(c_{3}\right)\right] \rho_{k} /(1-$ $\left.\rho_{1}-\rho_{2}\right)$. Generically, investors with search costs between cutoff values $c_{j}$ and $c_{j-1}$ account for a market share for fund $k$ equal to the following, if $k \geq j$ :

$$
\frac{\rho_{k}}{1-\rho_{1}-\ldots-\rho_{j-1}}\left[G\left(c_{j-1}\right)-G\left(c_{j}\right)\right] .
$$

The total market share for $k$ is then the sum of these values for all segments of the search cost distribution above $c_{k}$ :

$$
q_{k}=\rho_{k}\left[1-G\left(c_{1}\right)\right]+\frac{\rho_{k}}{1-\rho_{1}}\left[G\left(c_{1}\right)-G\left(c_{2}\right)\right]+\ldots+\frac{\rho_{k}}{1-\rho_{1}-\ldots-\rho_{k-1}}\left[G\left(c_{k-1}\right)-G\left(c_{k}\right)\right]
$$

Grouping common $G(c)$ terms, factoring out a $\rho_{k}$, and evaluating at $k=j$ yields expression (7) in the text.

\section{B. Derivatives of Demand Curves}

The generalized market share equations are given in (7):

$$
q_{j}=\rho_{j}\left[\begin{array}{l}
1+\frac{\rho_{1} G\left(c_{1}\right)}{1-\rho_{1}}+\frac{\rho_{2} G\left(c_{2}\right)}{\left(1-\rho_{1}\right)\left(1-\rho_{1}-\rho_{2}\right)}+\sum_{k=3}^{j-1} \frac{\rho_{k} G\left(c_{k}\right)}{\left(1-\rho_{1}-\ldots-\rho_{k-1}\right)\left(1-\rho_{1}-\ldots-\rho_{k}\right)} \\
-\frac{G\left(c_{j}\right)}{\left(1-\rho_{1}-\ldots-\rho_{j-1}\right)}
\end{array}\right]
$$

we want to take price derivatives of these equations. Notice is where prices enter into the equations: the indirect utilities provided by the funds include their prices, and these indirect utilities are in turn embodied in the cutoff search cost values $c_{1}, \ldots, c_{j}$ above.

So with this in mind we can take the price derivative of the above:

$$
\begin{aligned}
\frac{d q_{j}}{d p_{j}}=\frac{\rho_{1} \rho_{j} g\left(c_{1}\right)}{1-\rho_{1}} \frac{d c_{1}}{d p_{j}}+\frac{\rho_{2} \rho_{j} g\left(c_{2}\right)}{\left(1-\rho_{1}\right)\left(1-\rho_{1}-\rho_{2}\right)} \frac{d c_{2}}{d p_{j}}+\sum_{k=3}^{j-1} \frac{\rho_{k} \rho_{j} g\left(c_{k}\right)}{\left(1-\rho_{1}-\ldots-\rho_{k-1}\right)\left(1-\rho_{1}-\ldots-\rho_{k}\right)} \frac{d c_{k}}{d p_{j}} \\
-\frac{\rho_{j} g\left(c_{j}\right)}{\left(1-\rho_{1}-\ldots-\rho_{j-1}\right)} \frac{d c_{j}}{d p_{j}}
\end{aligned}
$$

Now recall from (4) that

$$
c_{j}=\sum_{k=j+1}^{N} \rho_{k}\left(u_{k}-u_{j}\right) .
$$

Combined with the fact that the derivative of the $u$ with respect to price is -1 , this implies

$$
\frac{d c_{r}}{d p_{j}}= \begin{cases}-\rho_{j}, & \text { if } r<j \\ \sum_{k=j+1}^{N} \rho_{k}, & \text { if } r=j \\ 0, & \text { if } r>j\end{cases}
$$

The above takes advantage of our normalization assumption, $d u_{j} / d p_{j}=-1$. Substituting this into (A.6) gives: 


$$
\begin{gathered}
\frac{d q_{j}}{d p_{j}}=-\frac{\rho_{1} \rho_{j}^{2} g\left(c_{1}\right)}{1-\rho_{1}}-\frac{\rho_{2} \rho_{j}^{2} g\left(c_{2}\right)}{\left(1-\rho_{1}\right)\left(1-\rho_{1}-\rho_{2}\right)}-\sum_{k=3}^{j-1} \frac{\rho_{k} \rho_{j}^{2} g\left(c_{k}\right)}{\left(1-\rho_{1}-\ldots-\rho_{k-1}\right)\left(1-\rho_{1}-\ldots-\rho_{k}\right)} \\
-\frac{\rho_{j} g\left(c_{j}\right) \sum_{k=j+1}^{N} \rho_{k}}{\left(1-\rho_{1}-\ldots-\rho_{j-1}\right)}
\end{gathered}
$$

This is equation (11) in the text.

In the special case of equal sampling probabilities $\left(\rho_{j}=1 / N \forall j\right)$, this simplifies to:

$$
\frac{d q_{j}}{d p_{j}}=-\sum_{k=1}^{j-1} \frac{g\left(c_{k}\right)}{N(N-k+1)(N-k)}-\frac{(N-j) g\left(c_{j}\right)}{N(N-j+1)} \text {. }
$$

\section{Pricing Second Order Condition}

From (9), the first-order condition for profit maximization is:

$$
q_{j}(p)+\left(p_{j}-m c_{j}\right) \frac{\partial q_{j}(p)}{\partial p_{j}}=0
$$

The second-order condition is then:

$$
\left(p_{j}-m c_{j}\right) \frac{\partial^{2} q_{j}(p)}{\partial p_{j}^{2}}+2 \frac{\partial q_{j}(p)}{\partial p_{j}}<0
$$

Since the second term is always negative, if $\partial^{2} q / \partial p^{2}<0$, then the condition is always satisfied.

What is this term? We know from (11) that:

$$
\frac{d q_{j}}{d p_{j}}=-\frac{\rho_{1} \rho_{j}^{2} g\left(c_{1}\right)}{1-\rho_{1}}-\frac{\rho_{2} \rho_{j}^{2} g\left(c_{2}\right)}{\left(1-\rho_{1}\right)\left(1-\rho_{1}-\rho_{2}\right)}-\sum_{k=3}^{j-1} \frac{\rho_{k} \rho_{j}^{2} g\left(c_{k}\right)}{\left(1-\rho_{1}-\ldots-\rho_{k-1}\right)\left(1-\rho_{1}-\ldots-\rho_{k}\right)}-\frac{\rho_{j}^{2} g\left(c_{j}\right) \sum_{k=j+1}^{N} \rho_{k}}{\left(1-\rho_{1}-\ldots-\rho_{j-1}\right)} .
$$

Differentiating gives:

$$
\begin{aligned}
& \frac{d^{2} q_{j}}{d p_{j}^{2}}=-\frac{\rho_{1} \rho_{j}^{2} g^{\prime}\left(c_{1}\right)}{1-\rho_{1}} \frac{d c_{1}}{d p_{j}}-\frac{\rho_{2} \rho_{j}^{2} g^{\prime}\left(c_{2}\right)}{\left(1-\rho_{1}\right)\left(1-\rho_{1}-\rho_{2}\right)} \frac{d c_{2}}{d p_{j}}-\sum_{k=3}^{j-1} \frac{\rho_{k} \rho_{j}^{2} g^{\prime}\left(c_{k}\right)}{\left(1-\rho_{1}-\ldots-\rho_{k-1}\right)\left(1-\rho_{1}-\ldots-\rho_{k}\right)} \frac{d c_{k}}{d p_{j}} \\
& -\frac{\rho_{j} g^{\prime}\left(c_{j}\right) \sum_{k=j+1}^{N} \rho_{k}}{\left(1-\rho_{1}-\ldots-\rho_{j-1}\right)} \frac{d c_{j}}{d p_{j}}
\end{aligned} .
$$

Using

$$
\frac{d c_{r}}{d p_{j}}= \begin{cases}-\rho_{j}, & \text { if } r<j \\ \sum_{k=j+1}^{N} \rho_{k}, & \text { if } r=j, \\ 0, & \text { if } r>j\end{cases}
$$

This simplifies to: 


$$
\frac{d^{2} q_{j}}{d p_{j}^{2}}=\frac{\rho_{1} \rho_{j}^{3} g^{\prime}\left(c_{1}\right)}{1-\rho_{1}}+\frac{\rho_{2} \rho_{j}^{3} g^{\prime}\left(c_{2}\right)}{\left(1-\rho_{1}\right)\left(1-\rho_{1}-\rho_{2}\right)}+\sum_{k=3}^{j-1} \frac{\rho_{k} \rho_{j}^{3} g^{\prime}\left(c_{k}\right)}{\left(1-\rho_{1}-\ldots-\rho_{k-1}\right)\left(1-\rho_{1}-\ldots-\rho_{k}\right)}-\frac{\rho_{j}\left(\sum_{k=j+1}^{N} \rho_{k}\right)^{2} g^{\prime}\left(c_{j}\right)}{\left(1-\rho_{1}-\ldots-\rho_{j-1}\right)}
$$

Or, in the equal-sampling-probability case,

$$
\frac{d^{2} q_{j}}{d p_{j}^{2}}=\sum_{k=1}^{j-1} \frac{g^{\prime}\left(c_{k}\right)}{N^{2}(N-k+1)(N-k)}-\frac{(N-j)^{2} g^{\prime}\left(c_{j}\right)}{N^{2}(N-j+1)} .
$$

This is more likely to be negative (and thus assure the SOC holds for product $j$ ) when the $g^{\prime}\left(c_{k}\right)$ are less than zero and $g^{\prime}\left(c_{j}\right)>0$. Intuitively, this means that the search cost p.d.f. is rising at $j$ 's product and falling at less attractive products with cutoff values further right on the distribution $(k<j)$ : an inverted-U shape. In general, however, the second order condition depends on the particular specification of the search cost distribution, which can be checked at candidate equilibrium values.

\section{Data Appendix}

The bulk of our performance and characteristic data on mutual funds comes from the CRSP mutual fund database for the years 1995-2000. This data includes a considerable amount of information about the funds (as mentioned previously, different share classes for the same asset pool are considered separate funds). Most of the data is compiled annually, but monthly information on returns and assets under management are also available. We observe the year the fund was established, the identity of the fund's manager and managing company, the starting date of the manager's tenure, and whether the fund in a given year. Annual performance and portfolio characteristics included in the data are income and capital gains distributions. Pricing information includes expense ratios; $12 \mathrm{~b}-1$ fees; and front, rear, and deferred load levels. We use this data to compute a number of supplementary variables for our analysis. These include fund age, the total number of funds managed by a fund's management company (including those outside the S\&P 500 index category), the average and standard deviation of monthly returns, and measures of gross return benchmarked to the return of the S\&P 500 index.

We supplement the CRSP data with mutual fund cost data from Lipper Analytical Services for 1995-2000. Lipper examines funds' year-end reports to gather cost data in a number of categories. These cost numbers are aggregated and combined with asset data to yield total annual costs. We have cost data for approximately $80 \%$ of our sample fund observations over 1995-2000.

Two measures are central to our empirical work: price and market share. Unfortunately, for mutual funds, neither concept is as straightforward as it often is for other products. Several central issues arise; we discuss those relevant to each measure in turn.

There are a number of ways in which mutual fund prices vary from traditional concepts of price. One of these is that, invariably, rather than being priced as a simple dollar level, mutual fund prices are fractional charges related to the size of asset flows into or stocks held in the fund. Furthermore, there are several dimensions along which mutual funds can be priced. All funds have an annual expense ratio. This is a percentage of investor assets 
that is withdrawn from the owner's account and used to reimburse the fund management company. Annual expenses include management, administrative, and in some cases 12b-1 (marketing and distribution) fees. Some funds also impose one-time loads, charged as a percentage of fund flows into or out of a fund. There are two types of loads typically employed by the industry. Front-end loads are charged at the time of a purchase of fund assets. Back-end (or deferred) loads, if applicable, are charged at a time of withdrawal.

Funds differ in both their chosen pricing instruments and their levels. Furthermore, because of the stock/flow distinction between annual fees and loads, as well as the timing discrepancy between front- and back-end loads, it is not a trivial matter to identify a single price for each fund. We use the approach, common in the literature, of measuring fund price by adding annual fees (the expense ratio) to one-seventh of the sum of all load levels. The one-seventh fraction is obtained from the stylized fact that a typical mutual fund account is held for about seven years. Loads are incurred only when there are flows into or out of a fund, not on any asset stocks held. Hence the price is meant to incorporate the shareholder's annualized cost of the load.

Market size is also less than empirically clear-cut in this industry. While market size measurement issues are not uncommon, they typically revolve around defining the boundaries of the market. In our case, however, this is secondary. What is more difficult is defining the unit of purchase. Assets may be a reasonable dimension along which to measure market shares, and the data is readily available. Using this measure implicitly assumes investors annually evaluate whether to continue holding their assets in a particular fund or to move them elsewhere. (This is further complicated by the fact that loads apply to flows but management fees apply to stocks.) Further, market shares in standard markets are typically defined as the share of total purchases accounted for by a producer; i.e., the flow, not the stock, as is the case with the asset-based measure. Unfortunately, our data does not allow straightforward measurement of gross fund purchases. Because we only measure total assets under management, we only observe net flows into a fund. Net flows hide the size of the gross flows underlying them, and gross inflows are the preferable measure to base flow-centered market shares upon. (For example, in our 2000 data, it was not uncommon to see negative net changes in fund assets over the course of the year. It is not exactly clear just how one could define a flow-based market share measure from these negative values.) This problem could be partially circumvented because we observe monthly asset and return data. Monthly net flows can be computed and summed by sign to obtain an aggregated measure of gross flows. We have run some specifications using these flow data (some of which are discussed in the paper) and found little qualitative difference from the asset-based measures in the results. 


\section{References}

Anderson, Simon P., André de Palma, Jacques-François Thisse. Discrete Choice Theory of Product Differentiation. Cambridge, MA: MIT Press, 1992.

Barber, Brad M., Terrance Odean, and Lu Zheng. "Out of Sight, Out of Mind: The Effects of Expenses on Mutual Fund Flows.” Working Paper, 2001.

Berry, Steven, James Levinsohn, and Ariel Pakes. "Automobile Prices in Market Equilibrium." Econometrica, 63(4), 1995, pp. 841-90.

Burdett, Kenneth and Kenneth L. Judd. "Equilibrium Price Dispersion.” Econometrica, 51(4), 1983, pp. 955-69.

Capon, Noel, Gavan J. Fitzsimons, and Russ Alan Prince. "An Individual Level Analysis of the Mutual Fund Investment Decision.” Journal of Financial Services Research, 10(1), 1996, pp. 59-82.

Carhart, Mark M. "On Persistence in Mutual Fund Performance." Journal of Finance, 52(1), 1997, pp. 57-82.

Carlson, John A. and R. Preston McAfee. "Discrete Equilibrium Price Dispersion.” Journal of Political Economy, 91(3), 1983, pp. 480-93.

Chevalier, Judith and Glenn Ellison. "Risk Taking by Mutual Funds as a Response to Incentives.” Journal of Political Economy, 105(6), 1997, 1167-1200.

Chevalier, Judith and Glenn Ellison. "Career Concerns of Mutual Fund Managers." Quarterly Journal of Economics, 114(2), 1999, pp. 389-432.

Dixit, Avinash K., and Joseph E. Stiglitz. "Monopolistic Competition and Optimum Product Diversity." American Economic Review, 67(3), 1977, pp. 297-308.

Eckstein, Zvi and Kenneth I. Wolpin. "Estimating a Market Equilibrium Search Model from Panel Data on Individuals." Econometrica, 58(4), 1990, pp. 783-808.

“Everyman, Farewell." The Economist, Jan. 10" 2002.

Falkenstein, Eric G. "Preferences for Stock Characteristics as Revealed by Mutual Fund Portfolio Holdings.” Journal of Finance, 51(1), 1996, pp. 111-35.

Flinn, Christopher J. and James J. Heckman. "New Methods for Analyzing Structural Models of Labor Force Dynamics.” Journal of Econometrics, 18(1), 1982, pp. 115-68. 
Foster, Lucia, John Haltiwanger, and C. J. Krizan. "The Link Between Aggregate and Micro Productivity Growth: Evidence from Retail Trade.” NBER Working Paper 9120, 2002.

Gruber, Martin J. "Another Puzzle: The Growth in Actively Managed Mutual Funds." Journal of Finance, 51(3), 1996, pp. 783-810.

Hong, Han and Matthew Shum. "Estimating Equilibrium Search Models." Working Paper. 2001.

Investment Company Institute. Fundamentals. Washington, DC. Various Issues, 1996-2000.

Investment Company Institute. Understanding Shareholders' Use of Information and Advisers. Washington, DC. 1997.

Investment Company Institute. Mutual Fund Fact Book. Washington, DC. 2000 and 2002.

Jensen, Michael C. "The Performance of Mutual Funds in the Period 1945-1964." Journal of Finance, 23(2), 1968, pp. 389-416.

Khorana, Ajay and Henri Servaes. "The Determinants of Mutual Fund Starts." Review of Financial Studies, 12(5), 1999, pp. 1043-74.

Khorana, Ajay and Henri Servaes. "An Examination of Competition and Investor Behavior in the Mutual Fund Industry.” Working Paper, 2001.

Klemperer, Paul. "Price Wars Caused by Switching Costs." Review of Economic Studies, 56(3), 1989, pp. 405-420.

Malkiel, Burton G. "Returns from Investing in Equity Mutual Funds 1971 to 1991." Journal of Finance, 50(2), 1995, pp. 549-72.

Mamaysky, Harry and Matthew Spiegel. "A Theory of Mutual Funds: Optimal Fund Objectives and Industry Organization." Yale ICF Working Paper 00-50, August 2001.

Mankiw, N. Gregory and Michael D. Whinston. "Free Entry and Social Inefficiency." Rand Journal of Economics, 17(1), 1986, pp. 48-58.

Massa, Massimo. "Why So Many Mutual Funds?" Working Paper, 2000.

McFadden, D. "Conditional Logit Analysis of Qualitative Choice Behavior." in P. Zarembka, ed., Frontiers in Econometrics. New York: Academic Press, 1974.

Petrin, Amil. "Quantifying the Benefits of New Products: The Case of the Minivan." Journal of Political Economy, 110(4), 2002, pp. 705-29.

Sirri, Erik R. and Peter Tufano. "Costly Search and Mutual Fund Flows." Journal of Finance, 53(5), 1998, pp. 1589-1622. 
Small, Kenneth A. and Harvey S. Rosen. "Applied Welfare Economics with Discrete Choice Models." Econometrica, 49(1), 1981, pp. 105-30.

Sorensen, Alan T. "Price Dispersion and Heterogeneous Consumer Search for Retail Prescription Drugs." UCSD Working Paper, 2001.

Stahl, Dale O. "Oligopolistic Pricing with Sequential Consumer Search.” American Economic Review, 79(4), 1989, pp. 700-12.

Stiglitz, Joseph E. "Competition and the Number of Firms in a Market: Are Duopolies More Competitive than Atomistic Markets?" Journal of Political Economy, 95(5), 1987, pp. 1041-61.

van den Berg, Gerard J. and Geert Ridder. "An Empirical Equilibrium Search Model of the Labor Market.” Econometrica, 66(5), 1998, pp. 1183-1221. 
Table 1: Price Dispersion within Fund Sectors

\begin{tabular}{|c|c|c|c|c|c|}
\hline Sector & $\mathrm{N}$ & $\begin{array}{l}\text { Mean } \\
\text { Price }\end{array}$ & $\begin{array}{l}\text { Coefficient of } \\
\text { Variation }\end{array}$ & $\begin{array}{l}75^{\text {th }} \text { to } 25^{\text {th }} \\
\text { \%ile Ratio }\end{array}$ & $\begin{array}{l}90^{\text {th }} \text { to } 10^{\text {th }} \\
\% \text { ile Ratio }\end{array}$ \\
\hline Aggressive Growth & 1278 & 191.0 & 0.485 & 2.0 & 3.1 \\
\hline Balanced Growth & 472 & 164.2 & 0.439 & 2.2 & 3.7 \\
\hline High-Quality Bonds & 862 & 118.1 & 0.566 & 2.5 & 4.9 \\
\hline High-Yield Bonds & 337 & 167.3 & 0.387 & 2.1 & 3.2 \\
\hline Global Bonds & 358 & 182.3 & 0.402 & 2.0 & 3.5 \\
\hline Global Equities & 452 & 228.3 & 0.374 & 1.6 & 2.8 \\
\hline Growth and Income & 978 & 158.4 & 0.830 & 2.5 & 5.5 \\
\hline Ginnie Mae & 182 & 144.0 & 0.460 & 2.4 & 4.0 \\
\hline Gov't Securities & 450 & 131.9 & 0.549 & 2.5 & 4.7 \\
\hline International Equities & 1267 & 225.5 & 0.432 & 1.9 & 3.2 \\
\hline Income & 218 & 170.8 & 0.415 & 2.2 & 3.4 \\
\hline Long-Term Growth & 1812 & 179.4 & 0.421 & 2.0 & 3.1 \\
\hline Tax-Free Money Mkt & 455 & 62.7 & 0.440 & 1.6 & 3.2 \\
\hline Gov't Securities Money Mkt & 437 & 59.5 & 0.611 & 1.8 & 4.8 \\
\hline High-Quality Muni Bond & 541 & 137.2 & 0.624 & 2.4 & 4.1 \\
\hline Single-State Muni Bond & 1326 & 150.3 & 0.384 & 1.7 & 3.6 \\
\hline Taxable Money Mkt & 541 & 79.2 & 0.726 & 2.0 & 7.1 \\
\hline High-Yield Money Mkt & 62 & 160.4 & 0.408 & 1.7 & 3.3 \\
\hline Precious Metals & 35 & 256.1 & 0.399 & 1.6 & 3.3 \\
\hline Sector Funds & 511 & 200.8 & 0.364 & 1.8 & 2.9 \\
\hline Total Return & 323 & 178.2 & 0.415 & 1.9 & 3.3 \\
\hline Utilities & 94 & 182.8 & 0.359 & 1.7 & 3.2 \\
\hline \multicolumn{6}{|l|}{ Selected Specific Sectors } \\
\hline Financial Sector & 67 & 206.5 & 0.291 & 1.4 & 2.5 \\
\hline Health Sector & 62 & 208.6 & 0.304 & 1.6 & 2.2 \\
\hline Tax-Free Bonds (California) & 135 & 143.5 & 0.399 & 1.9 & 3.6 \\
\hline Technology Sector & 172 & 199.4 & 0.349 & 1.7 & 2.8 \\
\hline
\end{tabular}

Note: Prices computed from CRSP data (annual fees + one-seventh of total loads) expressed in basis points. Data for 2000 . 
Table 2: Financial Homogeneity of Non-Institutional S\&P 500 Index Funds

\begin{tabular}{|c|c|c|c|c|c|c|c|}
\hline Variable & Statistic & 1995 & 1996 & 1997 & 1998 & 1999 & 2000 \\
\hline No. of Funds & & 23 & 24 & 36 & 54 & 65 & 76 \\
\hline \multirow{4}{*}{$\begin{array}{c}\text { Annual Gross } \\
\text { Return (\%) }\end{array}$} & Median & 37.45 & 22.88 & 33.27 & 28.75 & 20.88 & -8.98 \\
\hline & IQR & 0.31 & 0.30 & 0.20 & 0.26 & 0.21 & 0.32 \\
\hline & Mean & 37.43 & 22.67 & 33.24 & 28.95 & 20.95 & -8.63 \\
\hline & SD & 0.25 & 1.29 & 0.19 & 0.84 & 0.40 & 1.23 \\
\hline \multirow{4}{*}{$\begin{array}{l}\text { Avg. Gross } \\
\text { Monthly } \\
\text { Return (\%) }\end{array}$} & Median & 2.696 & 1.776 & 2.519 & 2.314 & 1.659 & -0.671 \\
\hline & IQR & 0.019 & 0.021 & 0.013 & 0.018 & 0.015 & 0.029 \\
\hline & Mean & 2.695 & 1.761 & 2.516 & 2.327 & 1.663 & -0.640 \\
\hline & SD & 0.016 & 0.090 & 0.012 & 0.056 & 0.029 & 0.113 \\
\hline \multirow{4}{*}{$\begin{array}{l}\text { Std. Dev. } \\
\text { Monthly } \\
\text { Returns (\%) }\end{array}$} & Median & 1.492 & 3.128 & 4.585 & 6.195 & 3.774 & 4.939 \\
\hline & IQR & 0.016 & 0.023 & 0.029 & 0.028 & 0.024 & 0.037 \\
\hline & Mean & 1.492 & 3.133 & 4.574 & 6.199 & 3.808 & 4.932 \\
\hline & SD & 0.025 & 0.038 & 0.050 & 0.051 & 0.115 & 0.219 \\
\hline
\end{tabular}

Note: Sample limited to funds reporting returns in every month of given year. 
Table 3: Evolution of Non-Institutional S\&P 500 Index Funds Price Distribution

\begin{tabular}{ccccccc} 
Statistic & 1995 & 1996 & 1997 & 1998 & 1999 & 2000 \\
\hline Number of Funds & 24 & 33 & 45 & 57 & 68 & 82 \\
Minimum & 19 & 18.0 & 16.0 & 17.0 & 17.0 & 9.45 \\
$10^{\text {th }}$ Percentile & 21.5 & 20.0 & 22.0 & 25.0 & 25.8 & 25.1 \\
$25^{\text {th }}$ Percentile & 43.8 & 45.0 & 40.0 & 46.0 & 47.1 & 47.0 \\
Median & 77.5 & 60.0 & 70.0 & 82.0 & 80.9 & 72.1 \\
$75^{\text {th }}$ Percentile & 120.5 & 123.1 & 136.3 & 136.3 & 152.9 & 144.8 \\
$90^{\text {th }}$ Percentile & 135.9 & 141.4 & 169.4 & 169.1 & 203.5 & 205.9 \\
Maximum & 206.4 & 206.4 & 231.4 & 231.4 & 235.4 & 268.4 \\
& & & & & & \\
Interquartile Range & 76.8 & 78.1 & 96.3 & 90.3 & 105.8 & 97.7 \\
$90^{\text {th }}-10^{\text {th }}$ Percentile Range & 115.9 & 121.4 & 147.4 & 144.1 & 177.7 & 180.8 \\
Mean & 82.4 & 80.6 & 89.8 & 94.2 & 104.2 & 97.1 \\
Asset-Weighted Mean & 26.8 & 26.6 & 26.0 & 28.9 & 31.9 & 32.2
\end{tabular}

Note: All prices in basis points.

Table 4. Decomposition of Asset-Weighted Average Price Growth

\begin{tabular}{cccccc} 
Year-to-Year Change & $1995-$ & $1996-$ & $1997-$ & $1998-$ & $1999-$ \\
& 1996 & 1997 & 1998 & 1999 & 2000 \\
\hline Growth in Asset-Weighted Mean Price & -0.190 & -0.575 & 2.881 & 3.040 & 0.295 \\
Within Component & -0.008 & -1.682 & -0.141 & -0.311 & 0.217 \\
Between-Fixed Prices & -0.425 & 1.152 & 0.415 & 0.440 & 0.464 \\
Between-Covariance & -0.037 & -0.569 & 0.056 & -0.020 & -0.221 \\
Entry & 0.280 & 0.524 & 2.551 & 3.131 & -0.159 \\
Exit & 0 & 0 & 0 & 0.200 & 0.006 \\
Net Entry Effect (Entry - Exit) & 0.280 & 0.524 & 2.551 & 2.931 & -0.165
\end{tabular}

Note: All measures are in basis points. 
Table 5: Search Model with Unequal Sampling Probabilities

\begin{tabular}{|c|c|c|c|c|c|}
\hline Parameters & (A) & (B) & (C) & (D) & (E) \\
\hline Log(Mean Search Cost $)$ & $\begin{array}{l}-6.17 \\
(0.06)\end{array}$ & $\begin{array}{l}-6.68 \\
(0.06)\end{array}$ & $\begin{array}{l}-6.10 \\
(0.05)\end{array}$ & $\begin{array}{l}-6.25 \\
(0.05)\end{array}$ & $\begin{array}{l}-6.33 \\
(0.11)\end{array}$ \\
\hline Variance of Logged Search Costs & $\begin{array}{c}1.88 \\
(0.03)\end{array}$ & $\begin{array}{c}2.07 \\
(0.06)\end{array}$ & $\begin{array}{c}1.84 \\
(0.03)\end{array}$ & $\begin{array}{c}1.85 \\
(0.06)\end{array}$ & $\begin{array}{c}1.95 \\
(0.04)\end{array}$ \\
\hline Mean Marginal Cost, basis points & $\begin{array}{c}4 \\
(1)\end{array}$ & $\begin{array}{l}12 \\
\text { (1) }\end{array}$ & $\begin{array}{c}3 \\
(1)\end{array}$ & $\begin{array}{c}5 \\
(1)\end{array}$ & $\begin{array}{c}4 \\
(1)\end{array}$ \\
\hline$\alpha$ & $\begin{array}{c}2.62 \\
(0.04)\end{array}$ & $\begin{array}{c}2.43 \\
(0.03)\end{array}$ & $\begin{array}{c}2.60 \\
(0.04)\end{array}$ & $\begin{array}{c}2.62 \\
(0.02)\end{array}$ & $\begin{array}{c}3.06 \\
(0.04)\end{array}$ \\
\hline$\gamma$ & & & & & $\begin{array}{c}0.11 \\
(0.03)\end{array}$ \\
\hline Time Trend of Mean Search Cost & $\begin{array}{l}-0.38 \\
(0.05)\end{array}$ & $\begin{array}{c}-0.50 \\
(0.04)\end{array}$ & $\begin{array}{l}-0.39 \\
(0.04)\end{array}$ & $\begin{array}{l}-0.39 \\
(0.02)\end{array}$ & $\begin{array}{c}-0.30 \\
(0.06)\end{array}$ \\
\hline Time Trend of Search Cost Variance & $\begin{array}{c}0.20 \\
(0.05)\end{array}$ & $\begin{array}{c}0.18 \\
(0.04)\end{array}$ & $\begin{array}{c}0.23 \\
(0.04)\end{array}$ & $\begin{array}{c}0.23 \\
(0.02)\end{array}$ & $\begin{array}{c}0.16 \\
(0.02)\end{array}$ \\
\hline $\mathrm{R}^{2}$, prices & 0.92 & 0.97 & 0.86 & 0.79 & 0.99 \\
\hline $\mathrm{R}^{2}$, quantities & 0.98 & 0.83 & 0.98 & 0.98 & 0.98 \\
\hline Median Search Cost (1996), b.p. & 21 & 12 & 22 & 19 & 18 \\
\hline Interquartile Search Cost Range (1996), b.p. & 5.9 to 75 & 3 to 50 & 6.4 to 77 & 5.5 to 67 & 4.7 to 67 \\
\hline Median Search Cost (2000), b.p. & 5 & 2 & 5 & 4 & 5 \\
\hline Interquartile Search Cost Range (2000), b.p. & 0.7 to 28 & 0.3 to 11 & 0.7 to 30 & 0.6 to 27 & 0.9 to 30 \\
\hline \multicolumn{6}{|c|}{$\begin{array}{l}\text { Specifications: } \\
\text { (A) All funds, asset-based market share, literature price } \\
\text { (B) All funds, flow-based market share, literature price } \\
\text { (C) Include only "A" shares for load funds, asset-based market share, literature price } \\
\text { (D) Include only "A" shares for load funds, asset-based market share, annualized price based } \\
\text { on } 10 \text { year holding period (for which "A" shares are optimal) } \\
\text { (E) Data as in model (A), but sampling probability is a function of both age and (logged) } \\
\text { total number of funds in management company }\end{array}$} \\
\hline
\end{tabular}


Table 6: Nonparametric estimates of search cost quantiles

\begin{tabular}{cccccc} 
Year & \multicolumn{5}{c}{ Percentile of Search Cost Distribution (basis points): } \\
\hline 1995 & $50^{\text {th }}$ & $75^{\text {th }}$ & $90^{\text {th }}$ & $95^{\text {th }}$ & $99^{\text {th }}$ \\
\hline 1996 & N/A & 8 & 20 & 49 & 103 \\
1997 & N/A & 4 & 16 & 23 & 102 \\
1998 & N/A & 2.5 & 14 & 34 & 133 \\
1999 & N/A & 2.5 & 16 & 44 & 140 \\
2000 & 0.6 & 2.2 & 35 & 60 & 188 \\
& 0.1 & 0.8 & 19 & 44 & 149
\end{tabular}


Table 7. Utility Function Estimates and Fund Attribute Summary Statistics

\begin{tabular}{|c|c|c|c|}
\hline Attribute & $\begin{array}{l}\text { Utility Weight, } \\
\text { basis points (s.e.) }\end{array}$ & Mean & Std. Dev. \\
\hline Constant & $\begin{array}{c}93.53 \\
(62.70)\end{array}$ & $\mathrm{N} / \mathrm{A}$ & $\mathrm{N} / \mathrm{A}$ \\
\hline Any Load Dummy & $\begin{array}{l}-12.11 \\
(23.73)\end{array}$ & 0.547 & 0.499 \\
\hline Rear/Deferred Load Dummy & $\begin{array}{l}59.57^{*} \\
(26.70)\end{array}$ & 0.272 & 0.446 \\
\hline Exchange-Traded Fund & $\begin{array}{l}199.5^{*} \\
(78.16)\end{array}$ & 0.023 & 0.149 \\
\hline Number Other Share Classes & $\begin{array}{l}2.726 \\
(7.966)\end{array}$ & 1.621 & 1.337 \\
\hline $\ln [$ No. Funds in Same Mgmt. Company] & $\begin{array}{l}30.97^{*} \\
(9.510)\end{array}$ & 4.259 & 1.215 \\
\hline $\ln [$ Fund Age] & $\begin{array}{l}99.39 * \\
(42.05)\end{array}$ & 1.393 & 0.728 \\
\hline Manager Tenure (yrs.) & $\begin{array}{c}3.578 \\
(8.746)\end{array}$ & 2.922 & 2.776 \\
\hline Income+Capital Gains Yield (\%) & $\begin{array}{l}-6.552 * \\
(3.212)\end{array}$ & 3.248 & 3.363 \\
\hline $\begin{array}{l}\text { Avg. Monthly \% Diff. btw. Fund and } \\
\text { S\&P } 500 \text { Returns }\end{array}$ & $\begin{array}{c}136.4 \\
(92.21)\end{array}$ & -0.026 & 0.106 \\
\hline Std. Dev. Monthly Returns (\%) & $\begin{array}{l}48.22 * \\
(7.495)\end{array}$ & 4.455 & 1.293 \\
\hline $\mathrm{N}$ & 309 & & \\
\hline $\mathrm{R}^{2}$ & 0.297 & & \\
\hline Mean of Dependent Variable & 582.9 & & \\
\hline
\end{tabular}

Notes: Fund age instrumented for using characteristics of other funds. See text for details. 
Table 8. Loss From Search

\begin{tabular}{cccc} 
Year & $\begin{array}{c}\text { Average Loss from } \\
\text { Buying Inferior } \\
\text { Funds, basis points }\end{array}$ & $\begin{array}{c}\text { Average Number of } \\
\text { Funds Searched }\end{array}$ & $\begin{array}{c}\text { Total Average } \\
\text { Expended Search } \\
\text { Costs, basis points }\end{array}$ \\
\hline 1995 & 42.1 & 9.3 & 23 \\
1996 & 35.4 & 12.6 & 19 \\
1997 & 30.7 & 16.4 & 14 \\
1998 & 28.2 & 19.4 & 12 \\
1999 & 37.5 & 22.1 & 8 \\
2000 & 15.6 & 24.8 &
\end{tabular}

Table 9. Logit Demand System Estimates and Welfare Implications

A. Utility Function Estimates

\begin{tabular}{ccc} 
Attribute & Estimated Utility Weight & Standard Error \\
\hline Constant & $-9.581^{*}$ & 0.849 \\
Price & $-0.020^{*}$ & 0.006 \\
Any Load Dummy & 0.014 & 0.550 \\
Rear/Deferred Load Dummy & $1.121^{*}$ & 0.301 \\
Exchange-Traded Fund & $4.733^{*}$ & 0.889 \\
Number Other Share Classes & 0.027 & 0.113 \\
ln(No. Funds in Same Mgmt. Company) & $0.451^{*}$ & 0.108 \\
ln(Fund Age) & $1.094^{*}$ & 0.549 \\
Manager Tenure & 0.126 & 0.106 \\
Income+Capital Gains Yield & -0.012 & 0.038 \\
Average \% Monthly Return Difference & $2.147^{*}$ & 1.077 \\
Std. Dev. Monthly Returns & -0.144 & 0.084 \\
\hline $\mathrm{N}$ & 309 & \\
$\mathrm{R}^{2}$ & 0.445 &
\end{tabular}

B. Implied Product Variety Welfare Loss of Vanguard Monopoly

\begin{tabular}{cc} 
Year & Loss (basis points) \\
\hline 1995 & 11.8 \\
1996 & 13.0 \\
1997 & 17.8 \\
1998 & 23.1 \\
1999 & 25.5 \\
2000 & 30.8
\end{tabular}


Table 10. Summary of Welfare Changes In Vanguard Monopoly Counterfactual

\begin{tabular}{|c|c|c|c|c|c|c|c|c|c|}
\hline & (1) & (2) & (3) & (4) & $\begin{aligned} & (5) \\
= & \$ 1.22 \mathrm{~m} \\
x & {[(1)-1] }\end{aligned}$ & $\begin{array}{c}(6) \\
=(2) \times(3)\end{array}$ & $\begin{array}{c}(7) \\
=(2) \times(4)\end{array}$ & $\begin{array}{c}(8) \\
=(5)+(6)+(7)\end{array}$ & $\begin{array}{c}(9) \\
=(8) \div(2)\end{array}$ \\
\hline Year & Funds & $\begin{array}{l}\text { Assets } \\
\text { (\$billion) }\end{array}$ & $\begin{array}{l}\text { Savings } \\
\text { from } \\
\text { Search } \\
\text { (b.p.) }\end{array}$ & $\begin{array}{l}\text { Product } \\
\text { Variety } \\
\text { Cost } \\
\text { (b.p.) }\end{array}$ & $\begin{array}{c}\text { Fixed Costs } \\
\text { Savings } \\
\text { (\$million) }\end{array}$ & $\begin{array}{l}\text { Savings } \\
\text { from } \\
\text { Search } \\
\text { (\$million) }\end{array}$ & $\begin{array}{l}\text { Product } \\
\text { Variety } \\
\text { Cost } \\
\text { (\$million) }\end{array}$ & $\begin{array}{c}\text { Net Welfare } \\
\text { Change } \\
\text { (\$million) }\end{array}$ & $\begin{array}{l}\text { Indifference } \\
\text { Monopolist } \\
\text { Price Change } \\
\text { (b.p.) }\end{array}$ \\
\hline 1995 & 24 & 22.0 & 65.1 & -11.8 & 28.1 & 143.2 & -26.0 & 145.3 & 66.1 \\
\hline 1996 & 33 & 39.4 & 54.4 & -13.0 & 39.0 & 257.7 & -51.2 & 245.5 & 62.3 \\
\hline 1997 & 44 & 70.6 & 44.7 & -17.8 & 52.5 & 315.6 & -125.7 & 242.4 & 34.3 \\
\hline 1998 & 57 & 118.0 & 40.2 & -23.1 & 68.3 & 474.4 & -272.6 & 270.1 & 22.9 \\
\hline 1999 & 68 & 174.8 & 42.5 & -25.5 & 81.7 & 742.9 & -445.7 & 378.9 & 21.7 \\
\hline 2000 & 82 & 163.8 & 23.6 & -30.8 & 98.8 & 386.6 & -504.5 & -19.1 & -1.2 \\
\hline
\end{tabular}


Figure 1.

Number and Assets of Retail S\&P 500 Index Funds

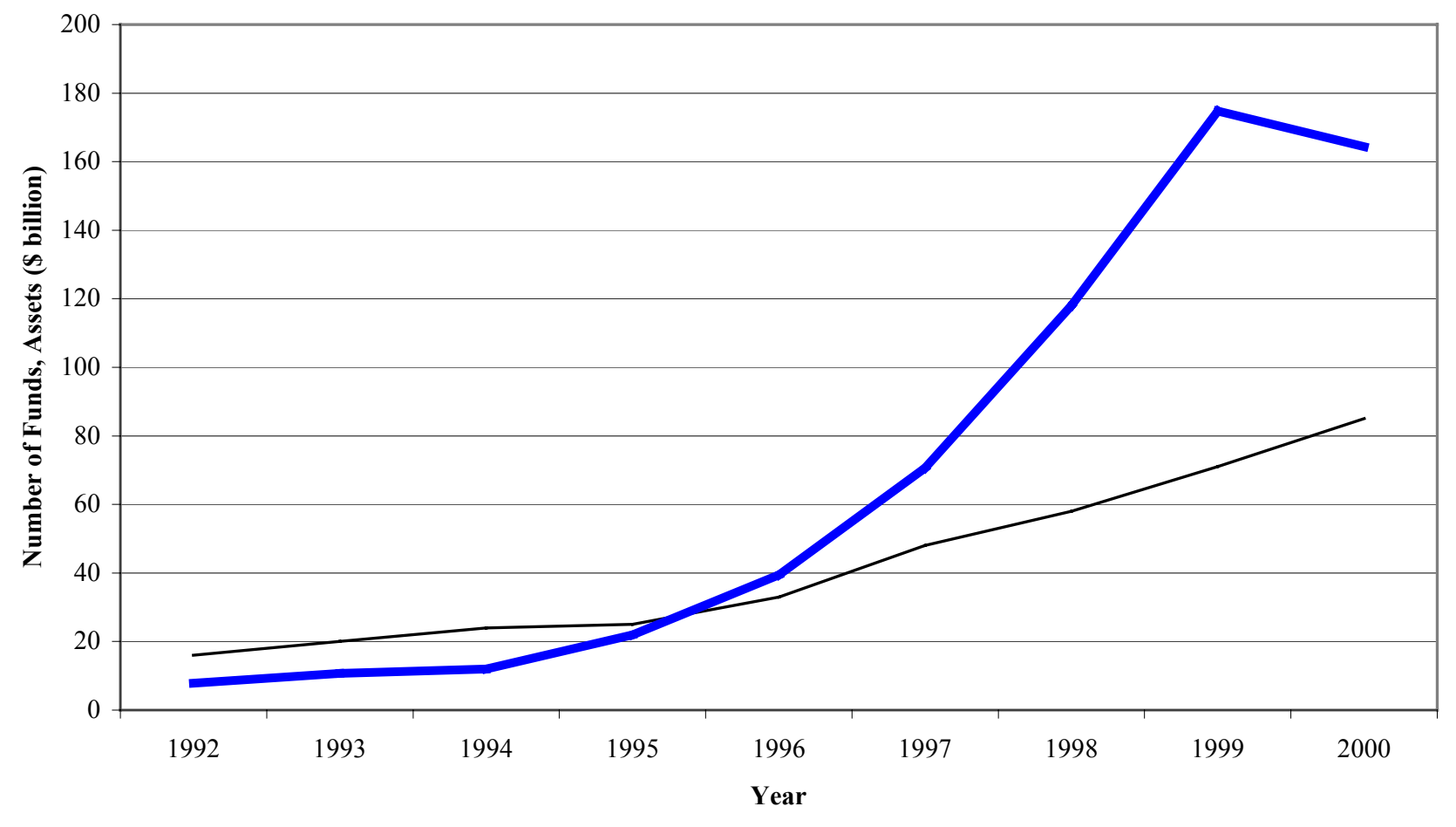

Number of Funds $\quad$ Assets (\$ billion) 
Figure 2.

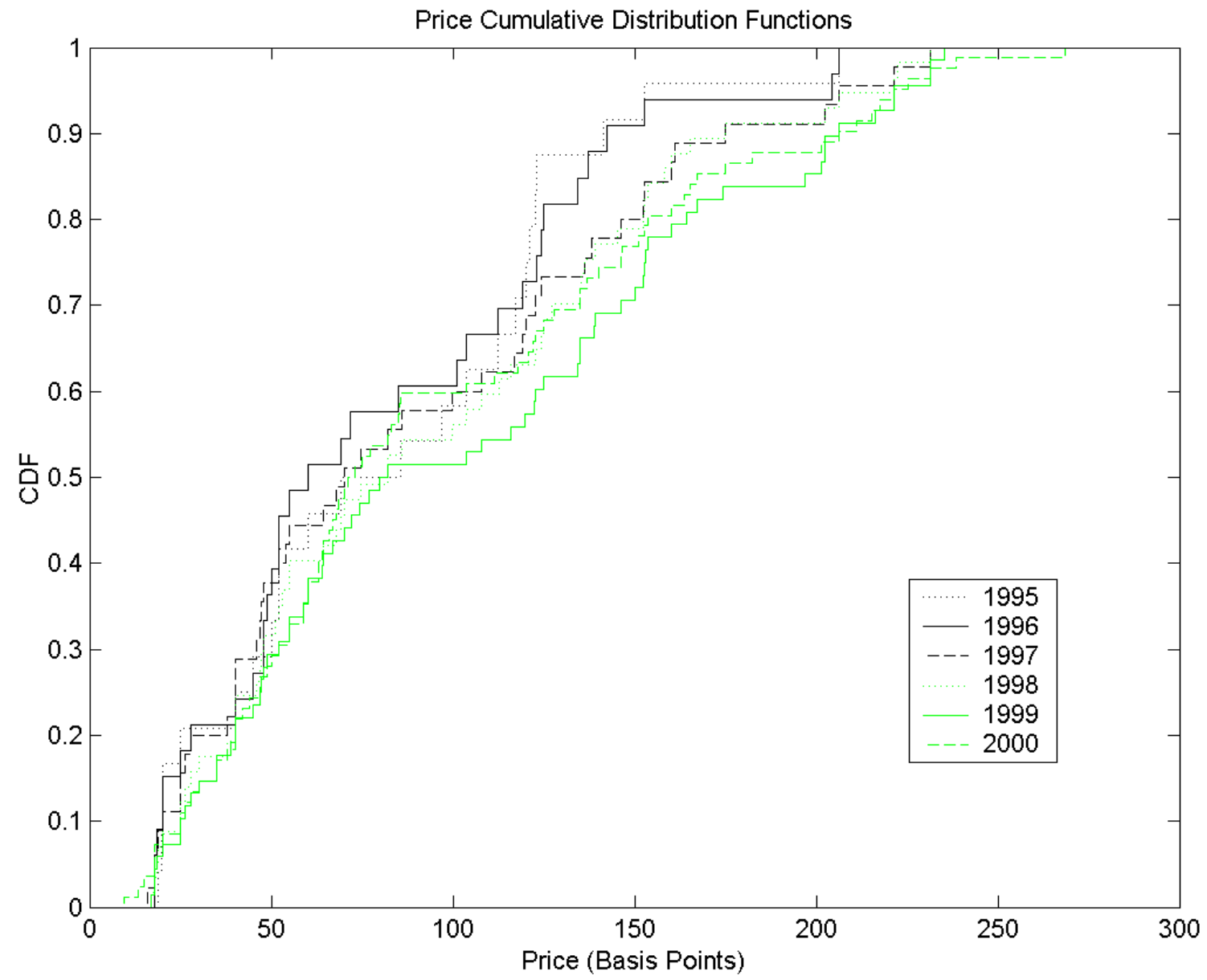


Figure 3.

Price Quantile Market Shares

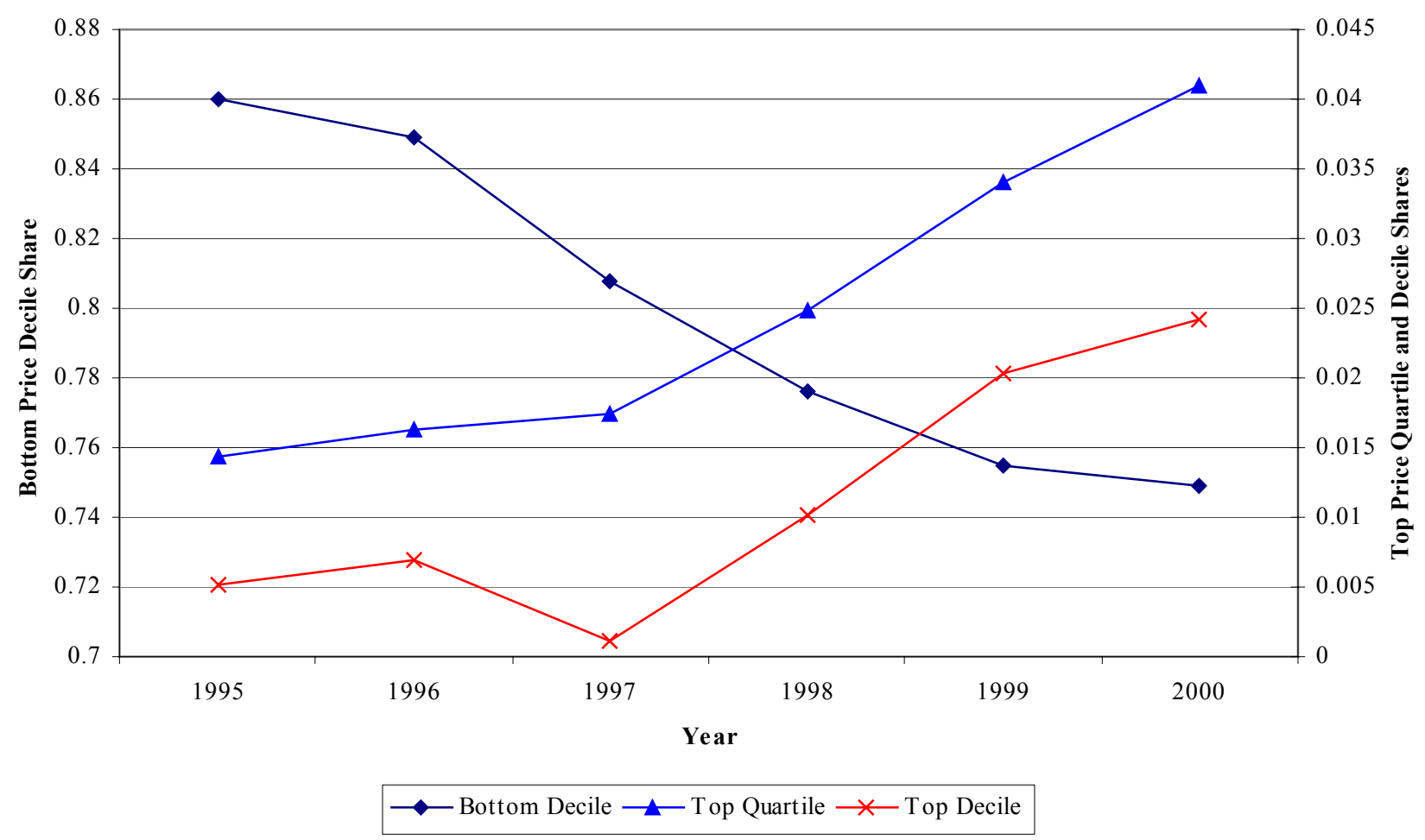


Figure 4.

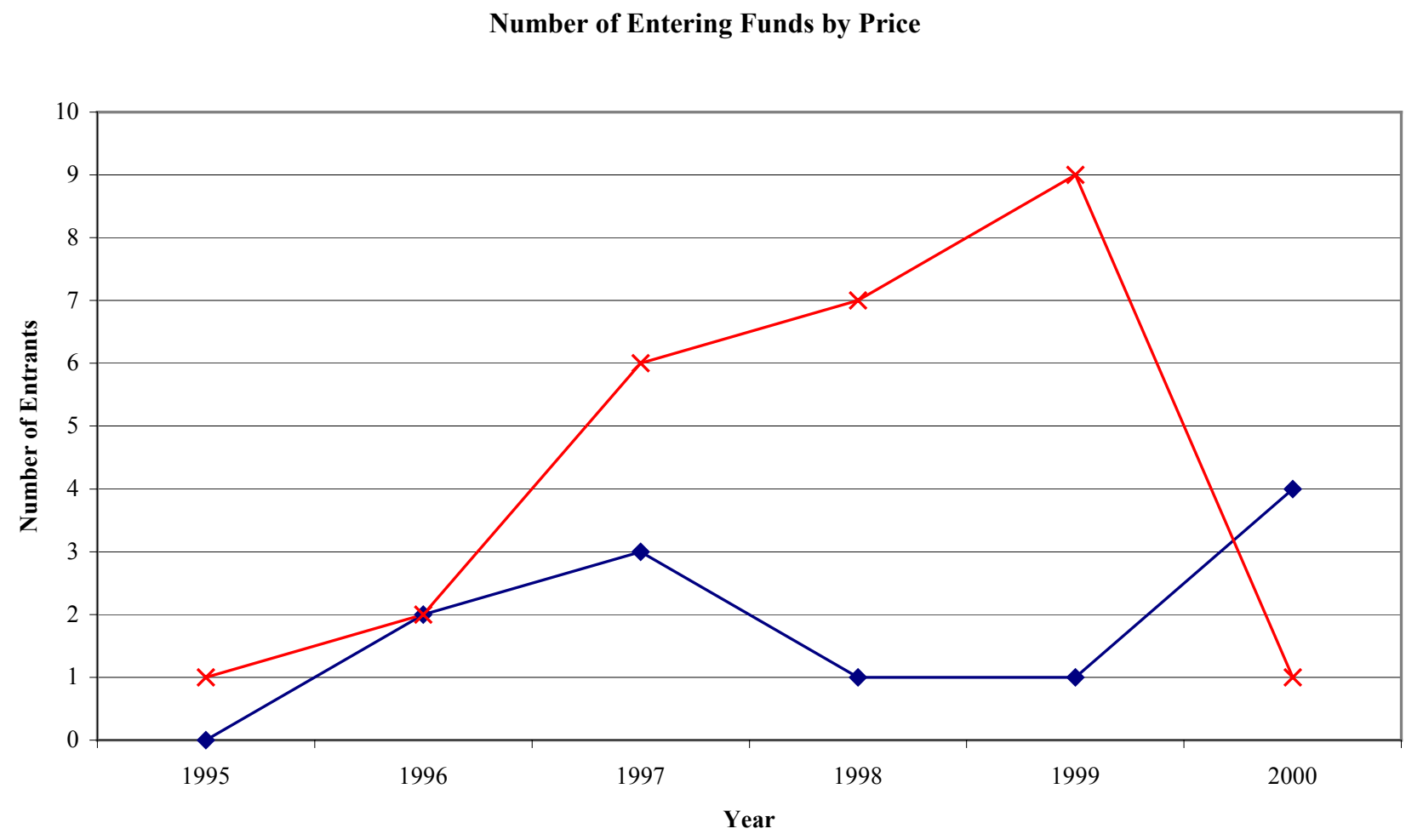

$\neg$ Price $<=40$ Basis Points $\longrightarrow$ Price $>=100$ Basis Points 
Figure 5.

2000 Price Histograms, Retail and Institutional Funds

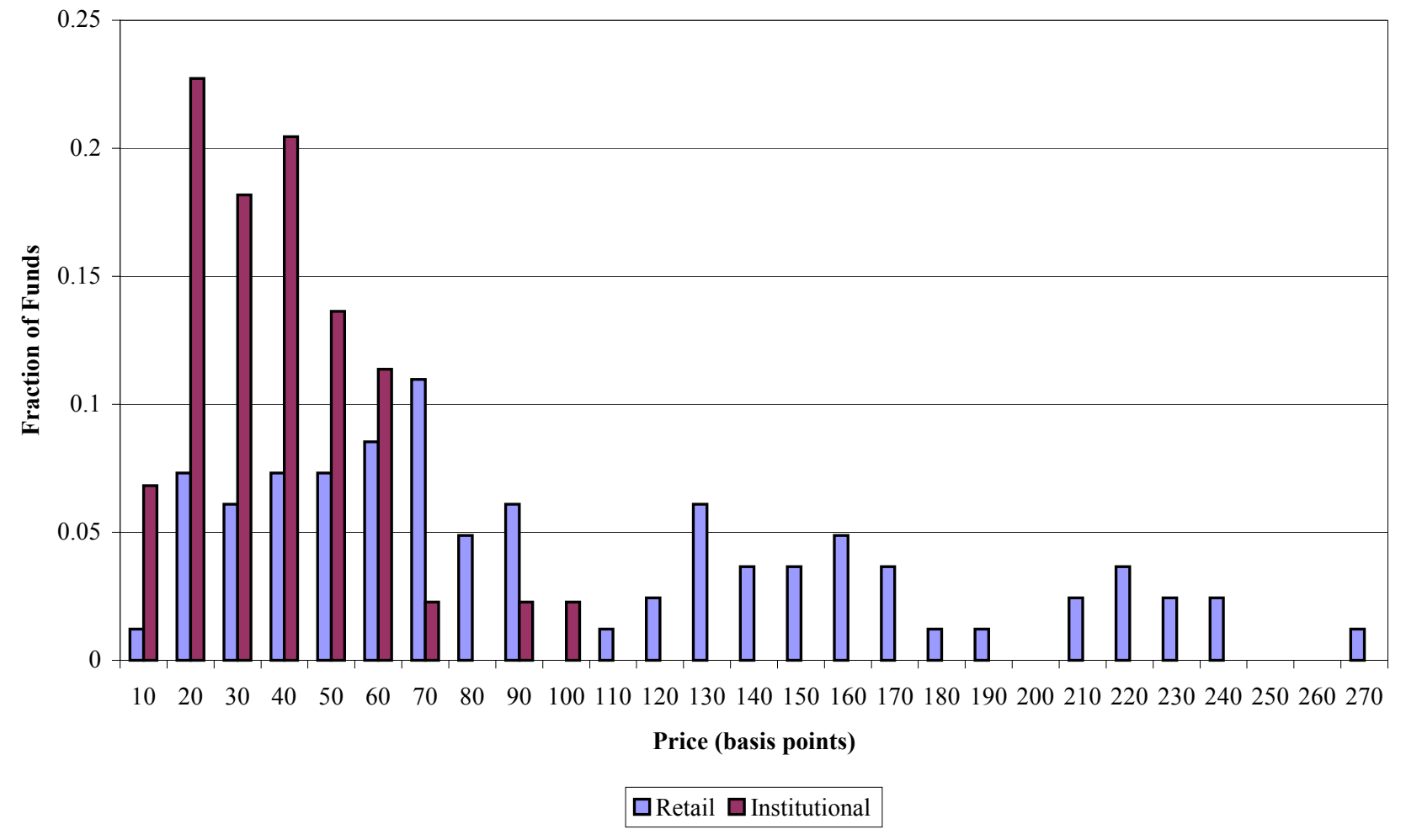


Figure 6.

Log Price vs. Log Market Share, 2000

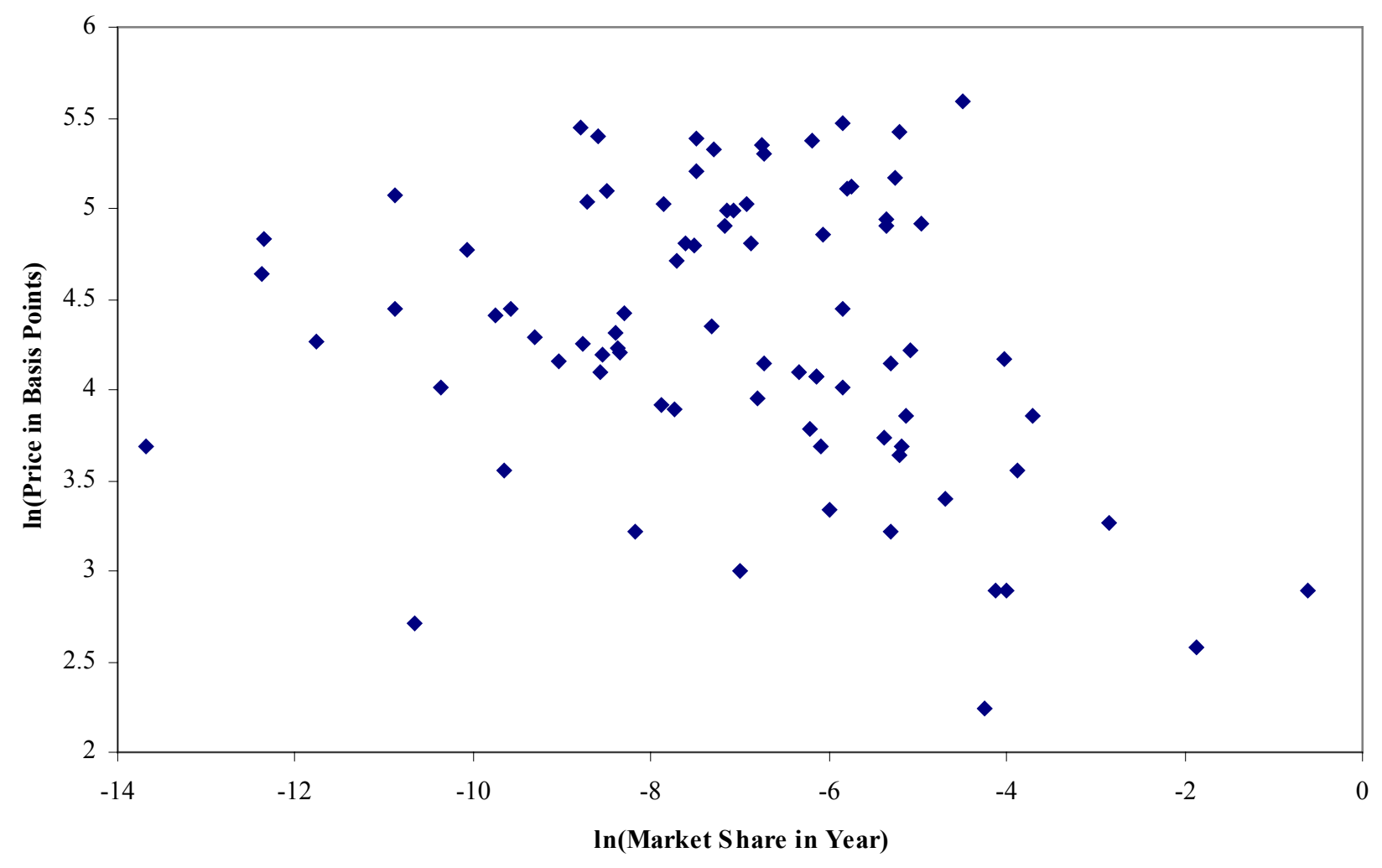


Figure 7.

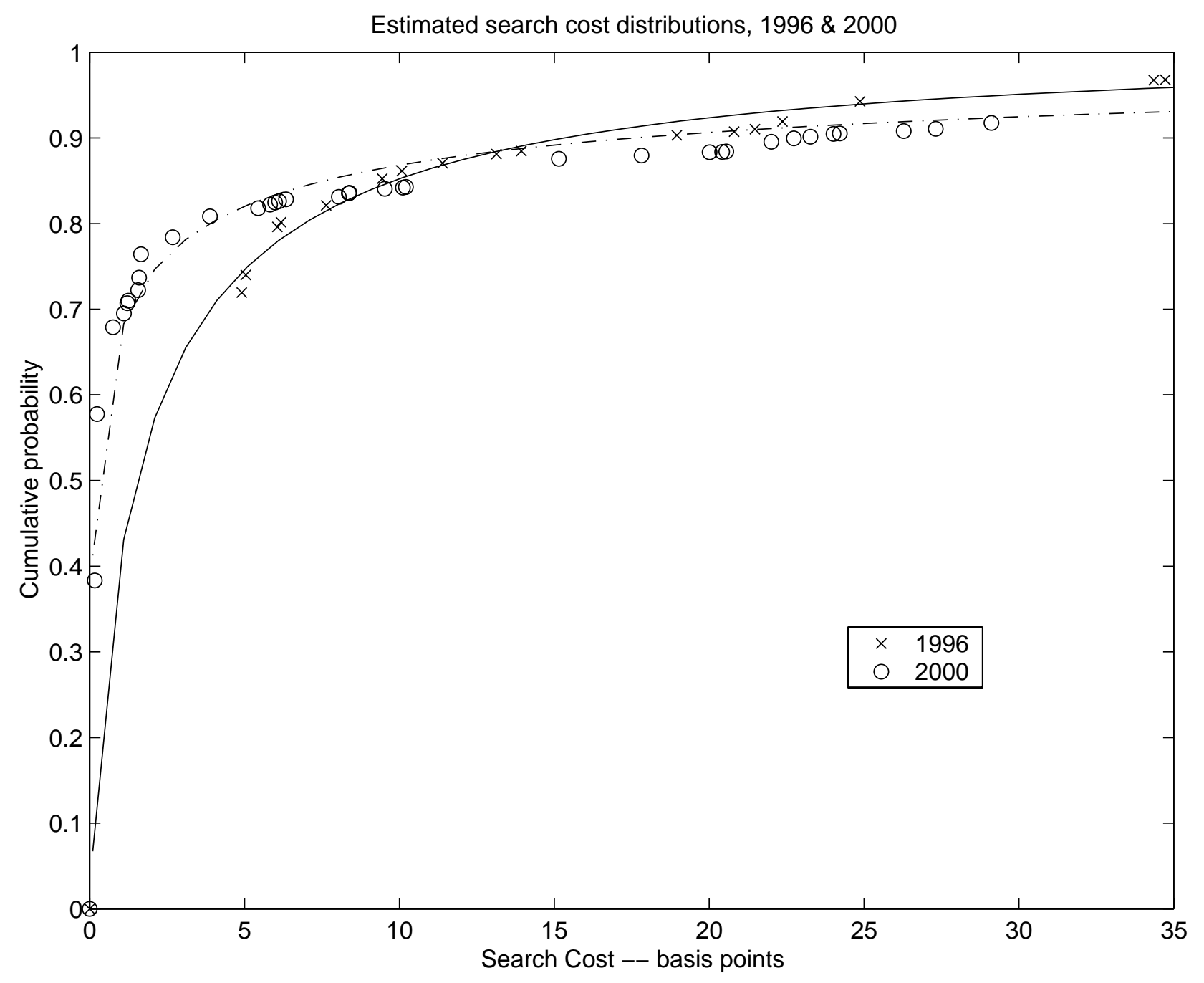

Notes: Solid line is parametric distribution for 1996, dashed line is parametric distribution for 2000 . 
Figure 8 .

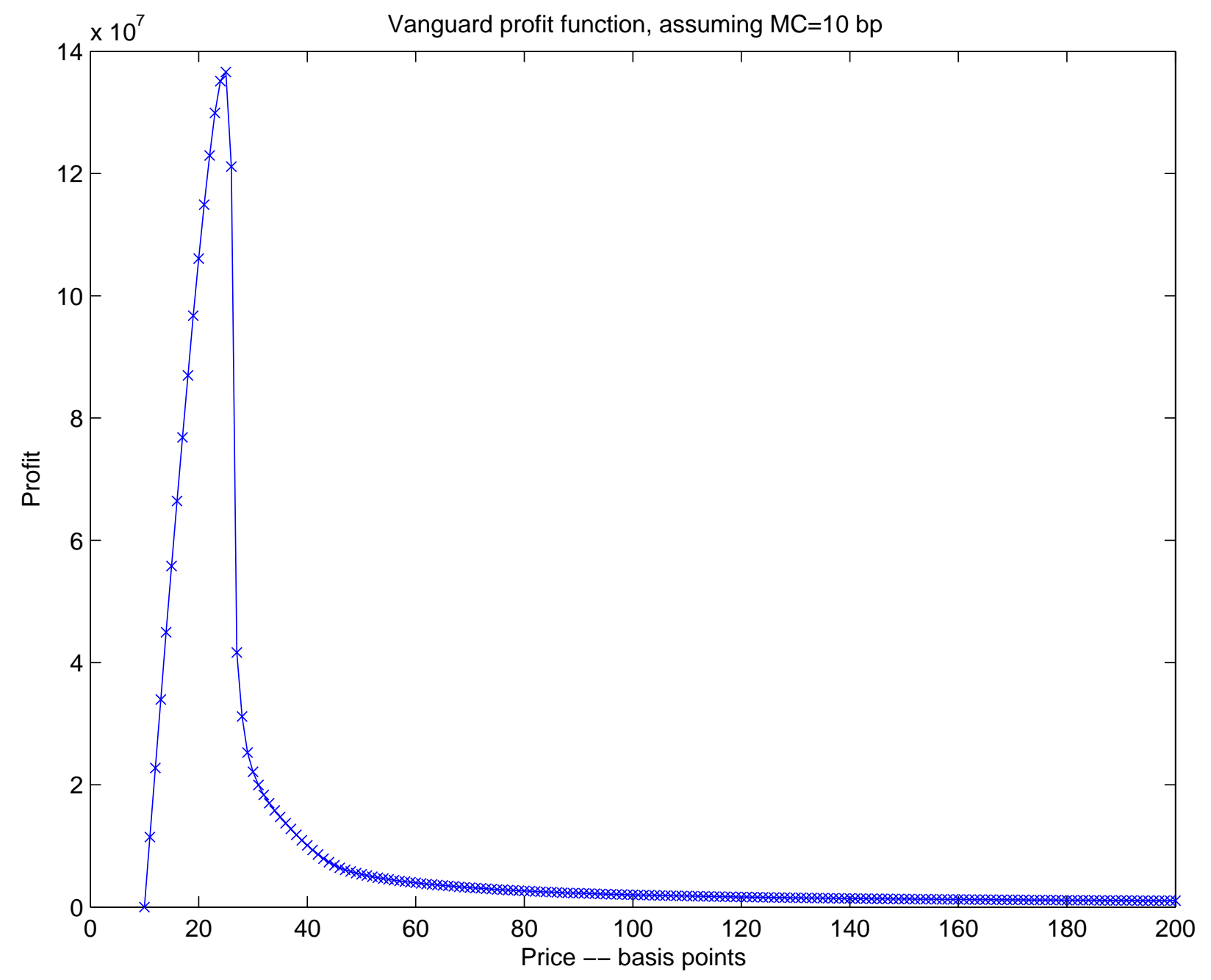


Figures 9a and 9b.
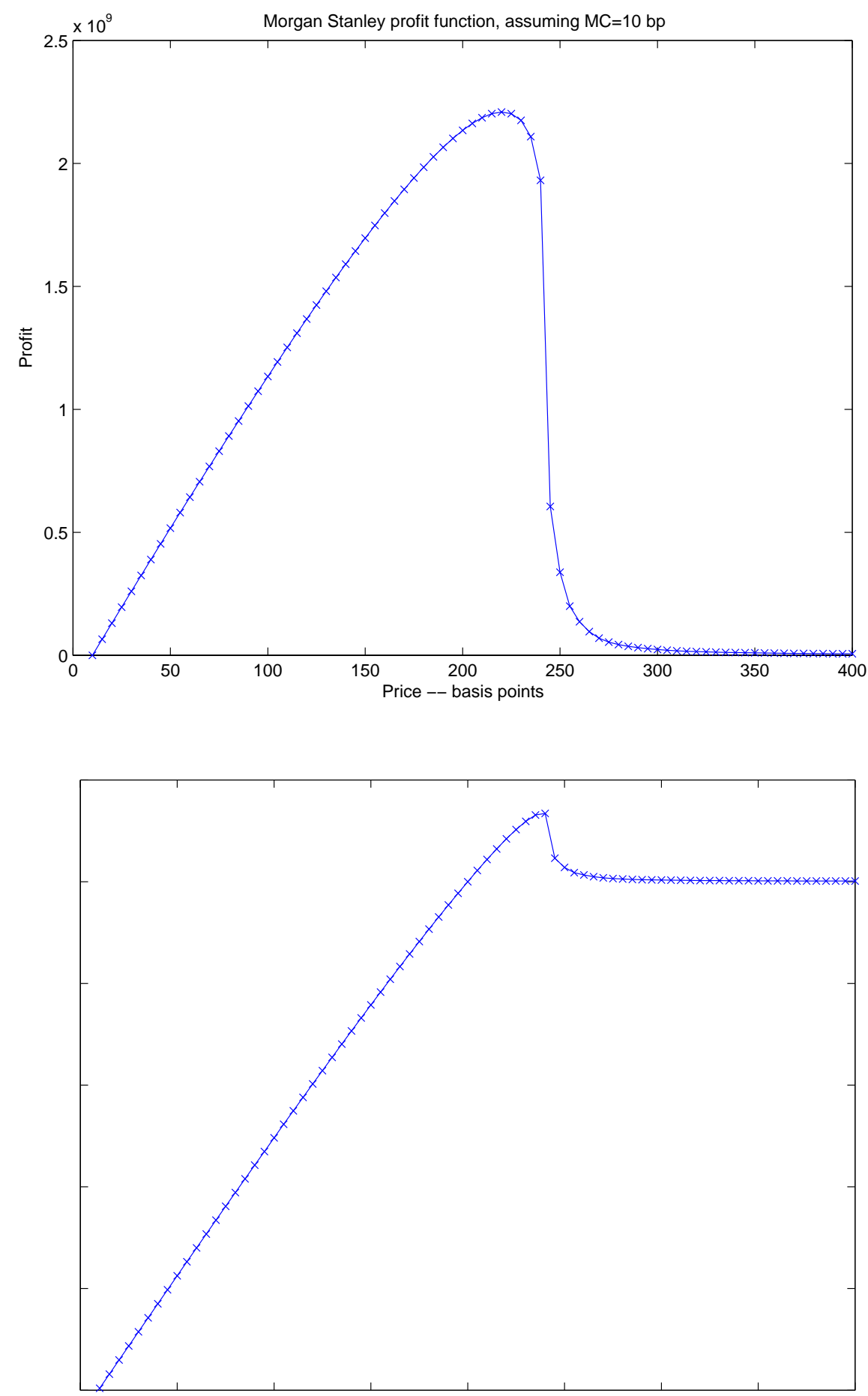
Figure 10.

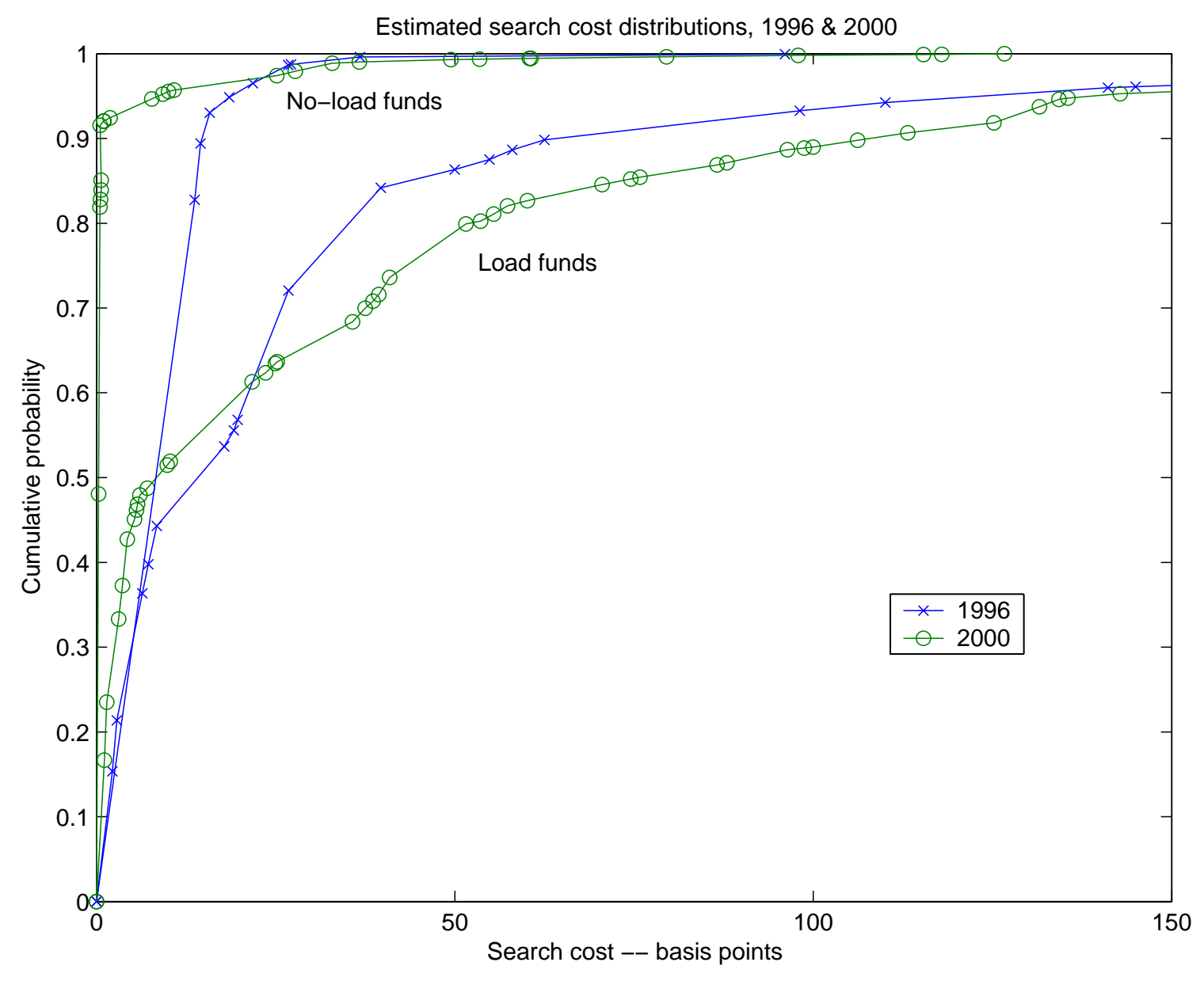

